\title{
الأزمات الاقتصادية في العلق أثناء حكم المغول وسبل معالجتها
}

\section{أ.م.د. اسراء مهدي مزيان}

جامعة واسط / كلية التربية

\section{المقدمة}

شهد العراق في العقد الأول من منتصف القرن السابع الهجري أحداثاً تأريخية غيَّرت الكثير من معالم حياته السياسية والإدارية والعسكرية تلك الأحداث التي وصل حد تأثيرها على المجتمع حضارياً وثقافياً

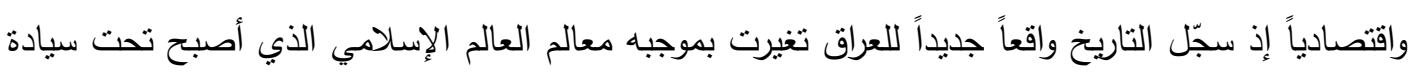
القوى المغولية والسلطة الإيلخانية بعد إسقاطها الخلافة العباسية واجتباحها لعاصمة العالم الإسلامي بغداد على يد المغول. - ملى

ومع دخول المغول إلى بغداد أصبحت بغداد وبقية المناطق الأخرى تحت السيادة الإيلخانية وبات

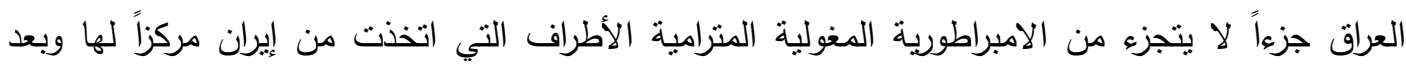

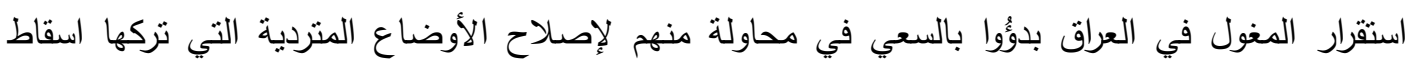

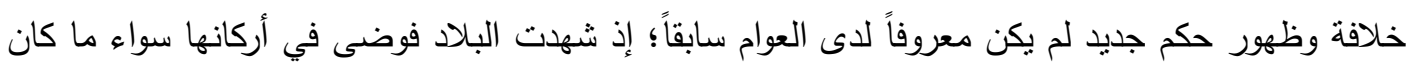

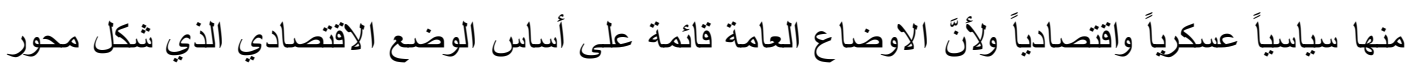
الحياة في العراق جاء بحثنا الموسوم بعنوان (الازمات الاقتصادية في العراق اثثاء حكم المغول وسبل معالجتها) لا سيّما أنَ البلاد شهدت العديد من الازمات الاقتصادية التي عصفت بها ومع بداية الاجتياح المغولي للعراق فقد حاولت السلطة المغولية تثبيت حكمها في العراق من خلال القيام بجملة من الإصلاحات

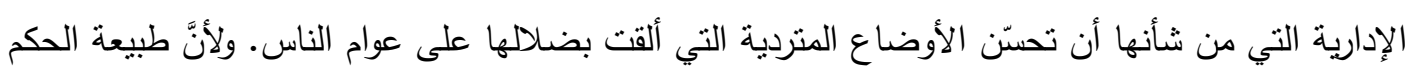

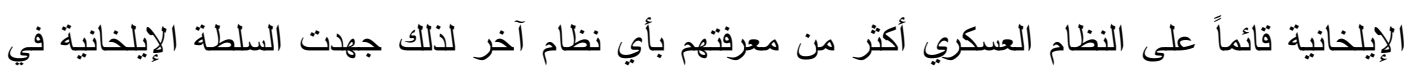


فرض نفوذهم على العراق باصلاحاتها الإدارية التي أنيطت لأشخاص ذو دراية ومعرفة بالحياة الإدارية أمثال

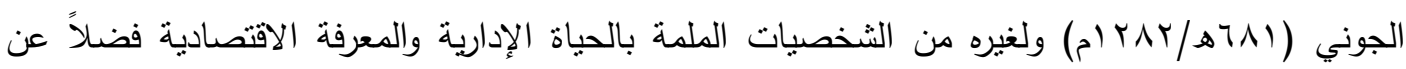

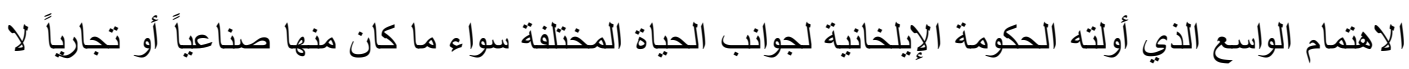

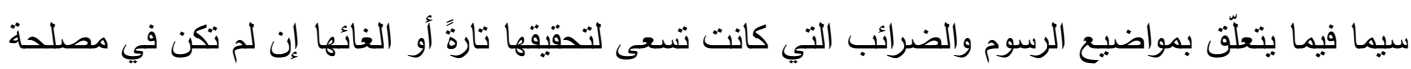

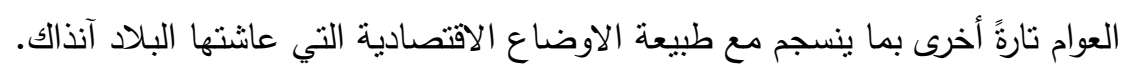

وارتأت طبيعة الدراسة تقسيم البحث لثلاثة محاور رئيسة ضم الدحور الأول لتسليط الضوء على طبيعة النظام السياسي وأثثر على الحياة الاقتصادية إبان النفوذ الدغولي للعراق في حين شمل الدحور الثاني

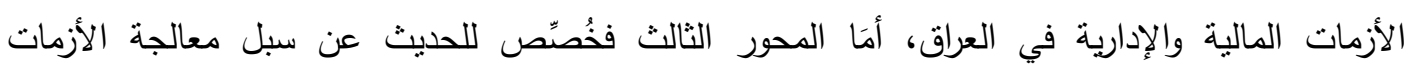
الاقتصادية في العراق خلال الحكم الإيلخاني، ثم جاءت الخاتمة لتقدم أهم النتائج التي نوصلنا إليها. واعتمدنا في بحثنا هذا على جمله من المصادر والمراجع وفي مقدمتها كتاب (الحوادث الجامعة

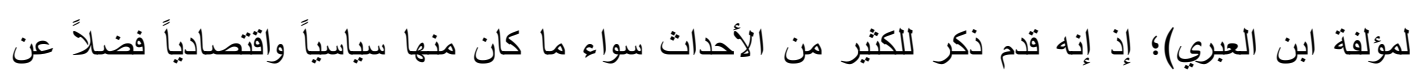

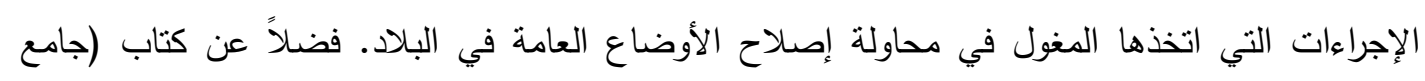
التواريخ لمؤلفة رشيد الدين فضل اله الهمذاني)؛ إذ قدّم لنا هذا الكتاب الكثير من الأحداث السياسية

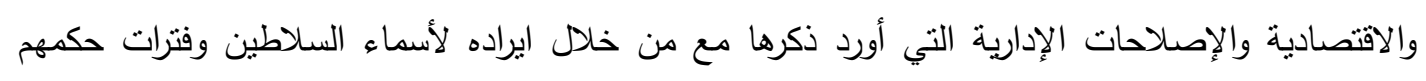
وأهم الأحداث التي عاشها حكام المغول الإيلخانيين. وإلى جانب المصادر قدمت لنا المراجع الكثير من الآراء والأفكار في محض الحديث عن الأزمات الاقتصادية والإصلاحات الإدارية في العراق إبان العصر الإيلخاني ككتاب (العراق في عهر المغول الإيلخانيين لمؤلفة جعفر خصباك) فضلاً عن كتاب (الحياة السياسية في الإني العراق في العصر الإيلخاني) لمؤلفهِ محمد صالح القزاز إلى جانب جملة من المصادر والمراجع أوردنا ذكرها في قائمة منفردة نهاية البحث. 
وفي الختام أرجو من الهه أن أكون وفقت في اعطاء صورة عن طبيعة الأزمات الاقتصادية التي عانشها العراق إبّان العصر الإيلخاني فما كان من قصور قد يرد في بحثنا فهو من صنع الإنسان وييقى الكمال لله جل في علاه.

الباحث 
(economic crises in Iraq during the rule of the Mongols and ways to Processed it

\section{Assistant Professor : Isra Mehdi Mizban}

مع دخول المغول إلى بغداد أصبحت وبقية المناطق الأخرى تحت السيادة الإيلخانية وبعد استقرار المغول في العراق بدأوا بالسعي في محاولة منهم لإصلاح الأوضاع الاقتصادية المتردية، وهو ما سنقق عليه في بحثنا المعنون (الازمات الاقتصادية في العراق اثناء حكم المغول وسبل معالجتها)، وارتأت طبيعة الدراسة تقسيم البحث لثناثة محاور رئيسة ضم المحور الأول لنسليط الضوء على طبيعة النظام السياسي وأثره على الحياة

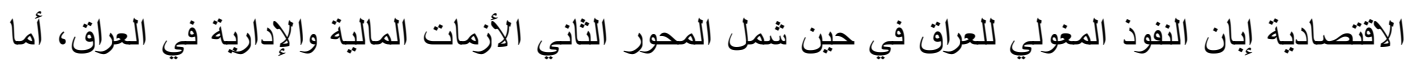
المحور الثالث فخصص للحديث حول سبل معالجة الازمات الاقتصادية في العراق خلال الحكم الإيلخاني،

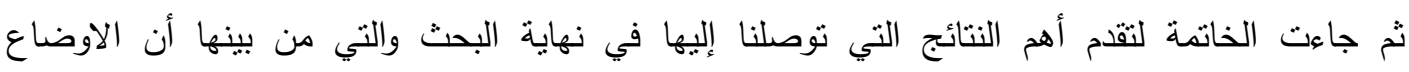
الاقتصادية ارتبطت بالاستقرار السياسي لذلك عاش العراق في ظل تردي الاوضاع السياسي ازمات اقتصادية

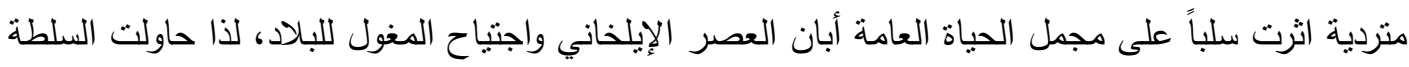
الإيلخانية عقب استقرارها في العراق انعاش الوضع الاقتصادي السيء، كما شعر سلاطين الهغول الإيلخانيين ان القوى العسكرية وحدها غير كافية لإدارة البلاد وتحقيق ما يسعون إليه لذلك لجأت السلطة الإيلخانية

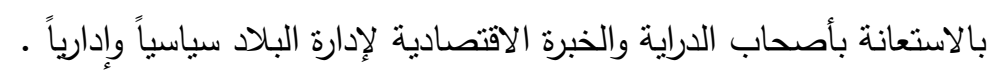

With the entry of the Mongols to Baghdad and the rest of the other areas became under the sovereignty of the Ilkhani, After the stability of the Mongols in Iraq began to try in an attempt to repair the deteriorating economic conditions, Which we will stand in our research entitled (economic crises in Iraq during the rule of the Mongols and ways to Processed it). The nature of the study considered the division of research into three main axes, which included the first axis to highlight the nature of the political system and its impact on economic life during the Mongol influence of Iraq, While the second axis included the financial and administrative crises in Iraq, The third axis was devoted to talk about ways to deal with the 
economic crises in Iraq during the rule of Ilkhani, Then came the conclusion of the progress of the most important findings we reached at the end of the research, among which That the economic conditions associated with political stability so Iraq lived in light of the deteriorating political situation, economic crises deteriorated adversely affected the overall public life during the Eilkhani era and the Mongol invasion of the country, Therefore, the Eilkhani authorities tried after their stability in Iraq to revive the bad economic situation. The sultans of the Mongolians felt that the military forces alone were not enough to run the country and achieve what they were seeking, so the Ekhkhani authorities resorted to the knowledge and economic expertise to manage the country politically and administratively.

\section{أولًً:- النّظام السياسيى وأثره على الهياة الاقتصادية بداية النفوذ المغولي اللعراق.}

إنِّ طبيعة النظام السياسي الذي عرفة العراق إبان النفوذ المغولي بدء مع ممارسة هولاكو نطاقاً

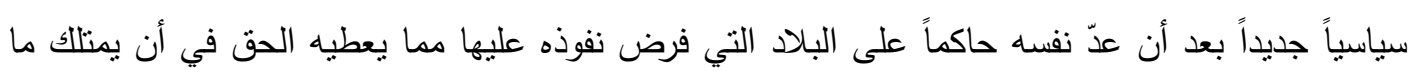
فتحه بقوة سيفه وشجاعة جنده.

وعلى الرغم من أنّ هولاكو كان رجل حرب وسيف وقتال ولم يكن يهوى السياسة الا أنّه كان مجبراً

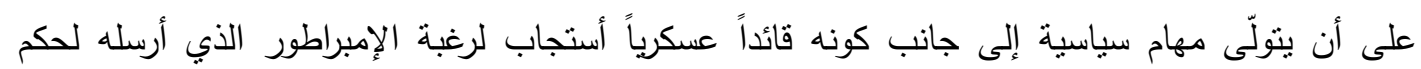

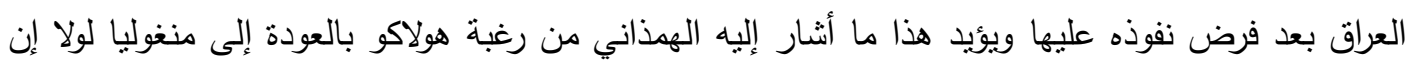

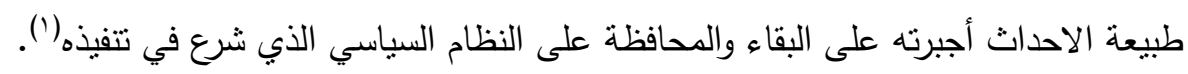

وبدء هولاكو مع ` دخوله بغداد ممارسته سلطته السياسية كنائب للإمبراطور منكو خان معتمداً على

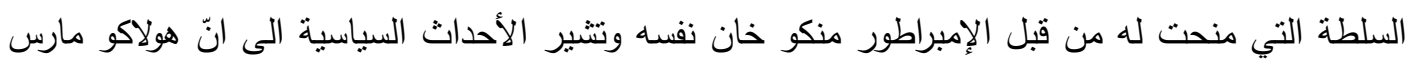

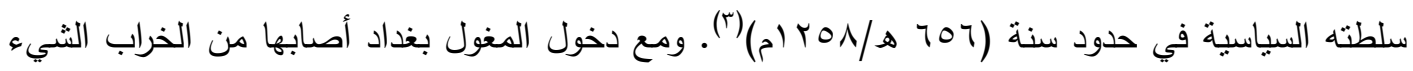


الكثير واختلفت الآراء في حقيقة الأحداث التي عاشتها بغداد أبان دخول المغول إليها فبعض المصادر تذكر

إن بغداد على يد هولاكو أصابها الخراب والحرق والدمار (\&).

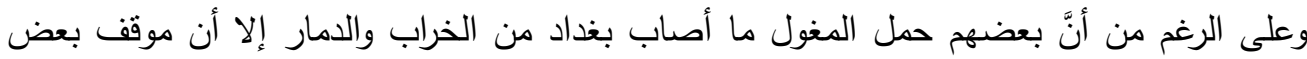
المؤرخين لاتكاد تتفق آرائهم حول حقيقة ما أصاب بغداد حيث برى بعض المؤرخين إنّ بغداد كانت تعاني

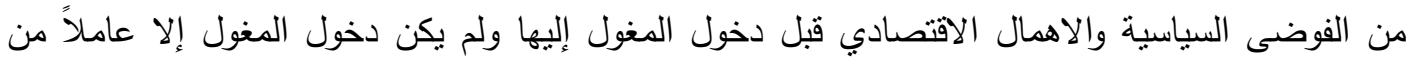

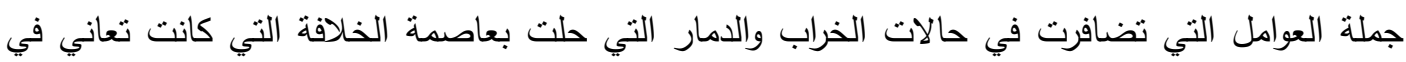
ظل خلفائها من الفوضى أيام حكم آخر خلفاء بني العباس(ْ).

وتثير بعص المصادر أنّ هولاكو نصح بالإبقاء على العاصمة دون إنزال الدمار فيها ،لأنّها ستكون

مركزاً لحكمة لذلك أبقى على ما بقي منها من بناء ويذكر بعضهم أنه أمر بإعادة ترميم بعض أبنيتها(؟). ولابّد من الإثشارة إلى أنّ دخول الدغول إلى بغداد رافقهُ شيء من الدمار والخراب بحكم كونه جيثاً دخل الددينة لأن الملوك إذا دخلوا قرية جعلوا أعزة أهلها أذل إلا أنّ هذا لا يعني إن هولاكو سعى إلى الدمار والخراب في مدينة بغداد لأنه كان بحاجه للإبقاء عليها كونها ستكون جزءاً من ممتلكات الإمبراطورية الدغولية فضلاً عن ذلك إن البلاد كانت تعيش حالات الفوضى السياسية والاقتصادية على أثز انشغال الخلافة بالصراعات السياسية التي كانت قائمة آنذاك وحالات الفقر والمجاعة التي ألدت بالبلاد على أثر إهمال الحياة الاقتصادية، فكل تلك العوامل مجتمعة هيأت الطريق لتسهيل دخول المغول البلاد وفرض نفوذها عليها.

ولم يقف تدهور الأوضاع عند حدّ انهيار النظام السياسي فحسب مع دخول المغول بغداد بل أُصِيْيَتْ الحياة الاقتصادية على اختلاف فروعها بالثلل التام بحكم حالة القلق التي كان يعاني منها الناس طيلة النفوذ

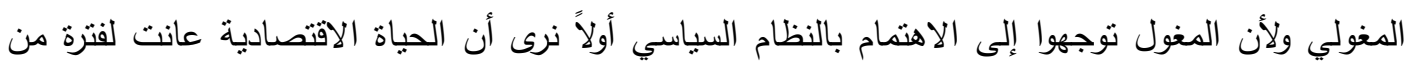

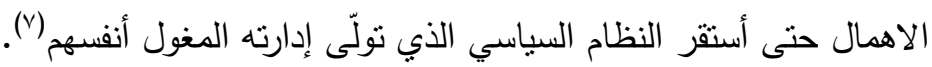


ففي الوقت الذي كانت فيه بغداد مركزاً للنشاط السياسي للعالم الإسلامي فمن بغداد كانت تصدر

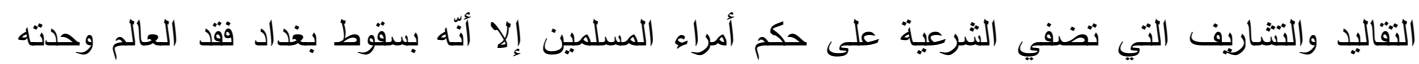
السياسية وفقدت العاصمة مكانتها في التوجيه والقيادة وتحولت بغداد من عاصمة جمعت تحت لوائها الوحدة

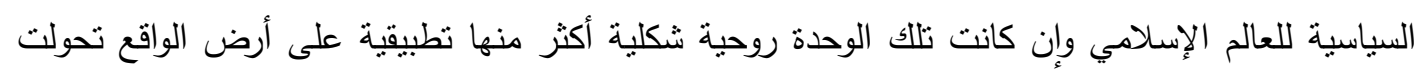

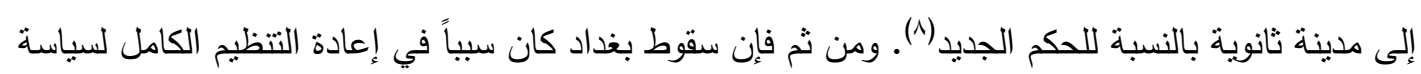
العالم فقد أوجد النفوذ المغولي حدود وتحالفات ومراكز جديدة للحكم وأصبحت القاهرة القبلة الجديدة للعالم الإسلامي إبان سقوط مركز الخلافة في بغداد(9).

\section{ثانياً:- الأزمات المالية والإدارية في العراق في ظلّ النفوذ المغوليّ.}

اضطربت أوضاع العراق العامة بسبب الحصار الذي فرضه الجيش المغولي على مدينة بغداد مما دفع هذا الأمر إلى نزوح أعداد كبيرة من أهالي العراق والمدن المجاورة كالحلة والكوفة إلى منطقة البطائح(") ومع حركة الهجرة التي شهدتها أغلب الأقاليم في العراق دفع هذا الأمر إلى أن فقد العراق مقوّماته السياسية

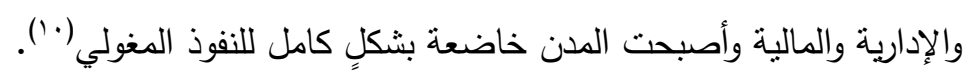

وبعد دخول المغول العراق أرسل هولاكو إلى مؤيد الدين ابن العلقمي، وعينه وزيراً وأسند ديوان العراق إلى فخر الدين الدمغاني، وقد أبقى المغول على الثقسيمات الإدارية في العراق على ما كانت عليه الدولة العباسية في أواخر عهدها بعدها عهر الدغول إلى دمج الوحدات الإدارية إلى وحدات رئيسة أكبر

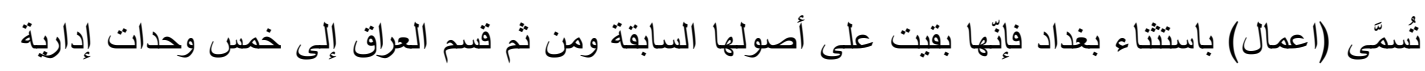
هي الأعمال الثرقية والأعمال الفرانية وأعمال الدجيل والمستتصري والأعمال الحلية والكوفية والأعمال الواسطية والبصرية(') الاعمئ)

"وفي ظل هذا التقسيم الإداري الذي أوردناه فقد كانت إدارة الإمبراطورية الإيلخانية لامركزية وكان

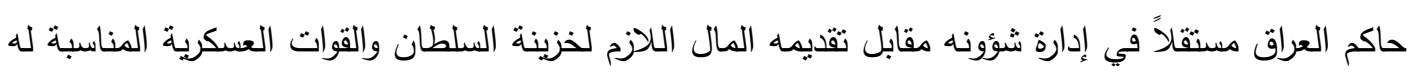


ساعة ظهور الخطر إلا أنَّ هذه اللامركزية لم تكن كاملة لأنَّ السلطان الإيلخاني كان يزور العراق ليطلع

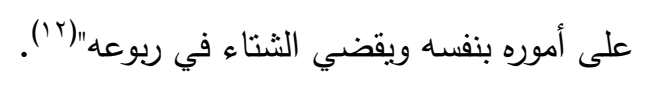

واعتمد طبيعة النظام المالي في العراق إبان دخول المغول إليها على نظام نقدي مزدوج كان بعمل به خلا السنين الأخيرة من العهد العباسي فقد مثلت أزدواجية هذا النظام على أساس الدينار الذهبي والدرهم

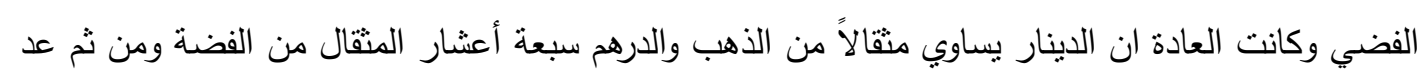

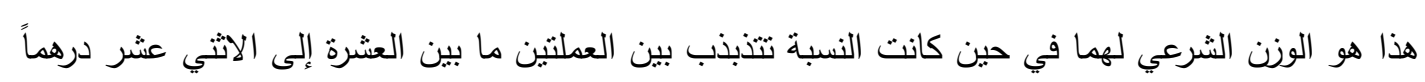
لكل دينار (r) (1r).

ومع ذلك التذبذب الذي شهده النظام النقدي اضطربت أحوال الاسواق التي انعكست سلباً على سوء الأحوال السياسية والاقتصادية التي عاثها العراق إبان دخول المغول إليها ولم يقف سوء الوضع الاقتصادي عند اقليم دون غيره بل غطت تلك الاوضاع غير المستقرة البلاد برمتها.

ومع دخول المغول بغداد ظل التعامل النقدي كما كان عليه في العهد العباسي الأخير على أساس الدينار الذهبي والدرهم الفضي واجزائهما واهمها الفلس وكان عمله نحاسية صغيرة(؛ (1).

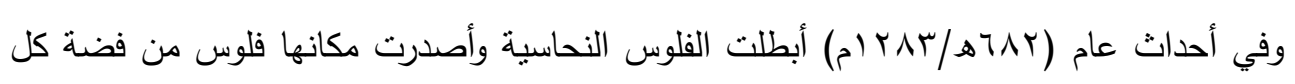

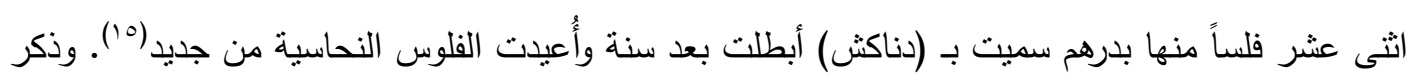

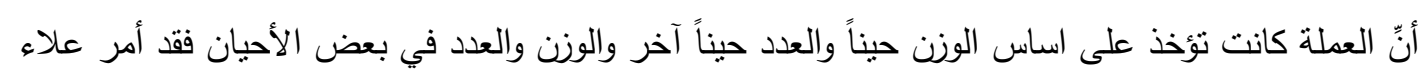

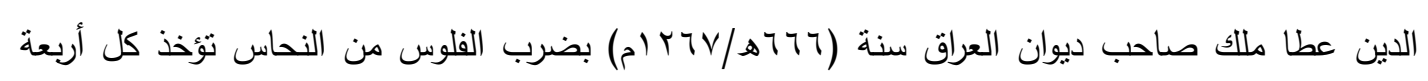
وعشرين فلساً منهم بدرهم وكل خمسة أرطال بدينار (ج').

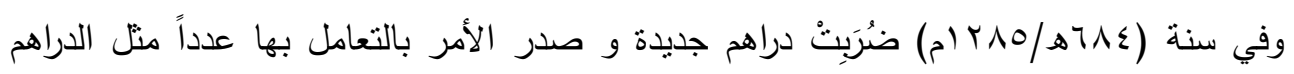
الابغانية(V). ومن ثم كانت النسبة بين الدينار والدرهم غير مستقرة بل تذبذبت تذبذباً شديداً حتى صارت

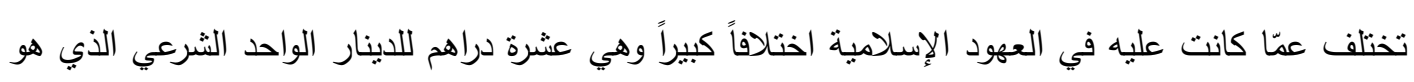




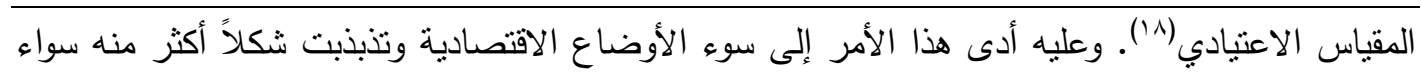

$$
\text { مما كانت عليه في الفترات السابقة. }
$$

ولطالما كانت العملة النقدية تتغير وفق آلية الحكم الذي يتولى إدارة العراق ففي سنة

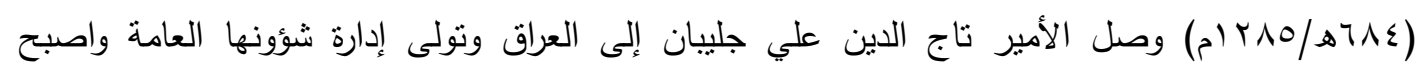

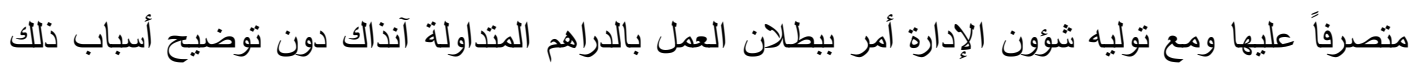

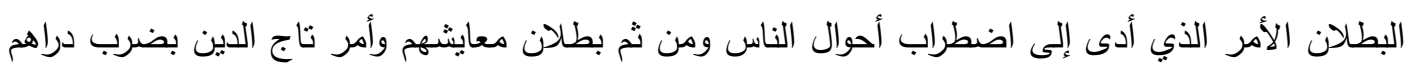

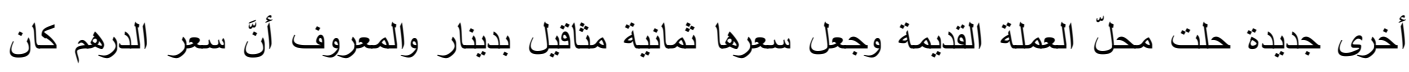
يساوي قبل ضرب العملة الجديدة سبعة أعشار الدثقال ومع هذا الاختلاف بين سعر الدرهم القديم والدرهم

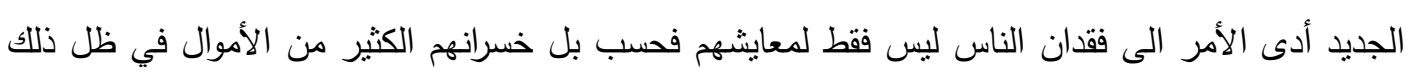
الاختلاف بضرب العملة النقدية الجديدة(19).

وذكر أنَّ الدينار في العراق كان من نوعين أحدهما يُسَّىى العوال(·r)، والثاني يسمى الدينار

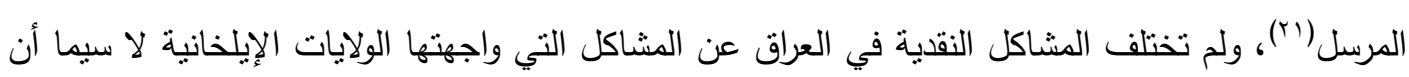
العراق مع دخول المغول إليه لم يعد دولة مستقلة له حكومته الخاصة به التي تصدر عمله واحدة لكل

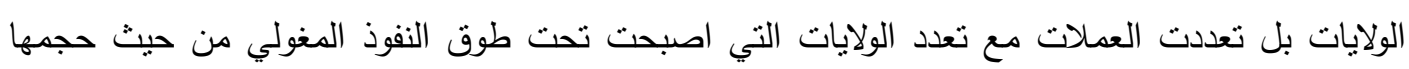
ووزنها ونقائها فأصبح لكل ولاية عملتها الخاصة المتداولة فيها والتي تختلف عن بقية الولايات الأخرى.

وأثارت المصادر التاريخية الى أنَّ العراق لم يتعامل بغير الدينار والدرهم على الرغم من وجود

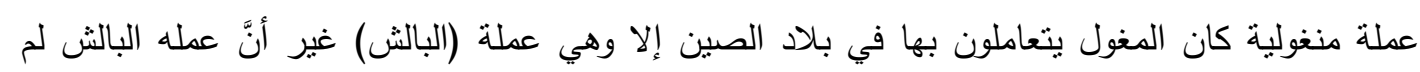

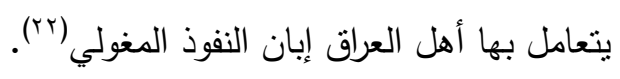

ومع سوء التعامل النقدي في العراق خلال الوجود المغولي فقد حاول بعض السلاطين القيام ببعض الإجراءات التي من شأنها أن تحسن الوضع الاقتصادي ولعلّ من تلك الاجراءات قيام السلطان غازان على بلى 
توحيد العملة في جميع انحاء الإمبراطورية الإيلخانية وإصلاحها وضمان سلامنها من الغش فضلاً عن ذلك الكابع

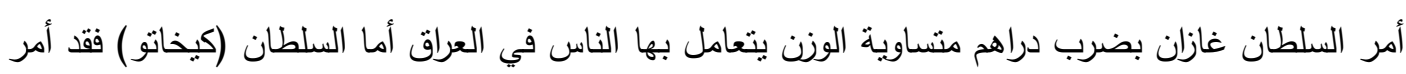

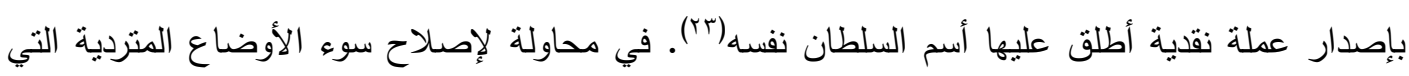

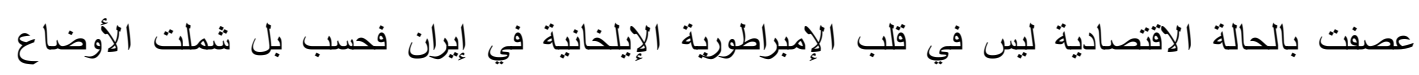

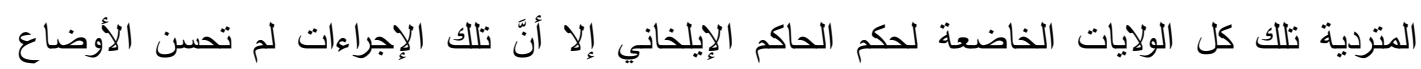

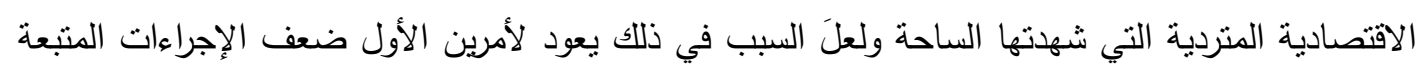

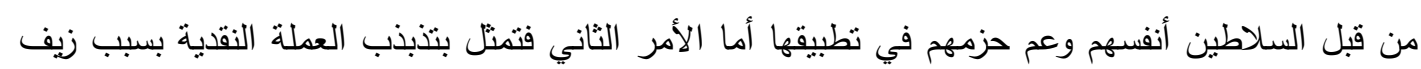
العملة والتنليس الذي شمل ثللك العملات بثكلٍ أضعف حجم التعامل النقاي بها في عموم البلاد التابعة للحكم الإيلخاني.

وفي ظلّ النفوذ المغولي أظهر الحكام الإيلخانيين اهتمامهم الواضح بالمسكوكات النقدية وتعودوا

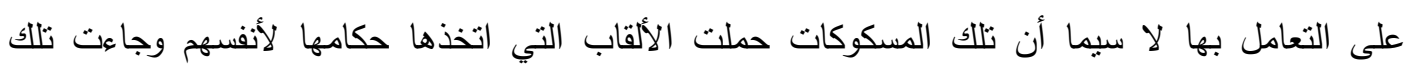
الألقاب نتيجة لتوسع نفوذ السلاطين في حكمه للبلاد أو أنَّهم ورثوها عند نوليهم عرش البلاد، وتميز الدينار المنغولي عن الدينار المضروب في العصر العباسي أي الدينار المنغولي وهو حذف اسم الخليفة العباسي

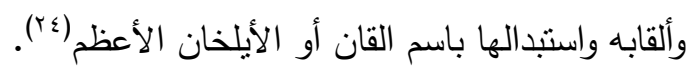

وعمل الحكام الإيلخانيين على حذف بعض الآيات القرآنية التي كانت تحيط بوجهي العملة وأبقوا

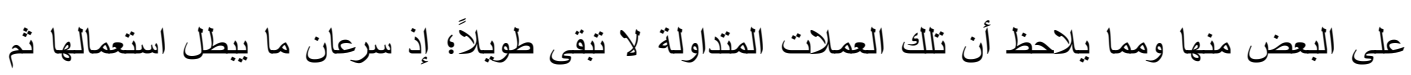
يتم سك عمله أخرى بعد مرور فنرة زمنية قد لا تتعدى السنة(ro).

ولا بد من الإثارة إلى أنَّ النطور الكبير الذي حدث للعملة النقدية ولاسيما الدينار الذهبي حصل في

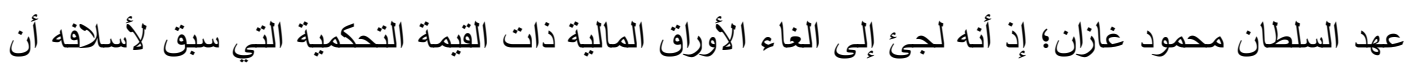
أحدثوها على الطريقة الصينية. كما أمر بجمع كل العملات المغشوشة في كل البلاد الإيلخانية وكسرها وإعادتها إلى دور الضرب ليعاد سكّها من جديد بدون غش أو تزيف كاملة المعيار (Tr). 
أمّا في عهد السلطان خذا بنده(YY)، فإنه أتخذ هو الأخر جملة من الإجراءات في باب الاصلاحات

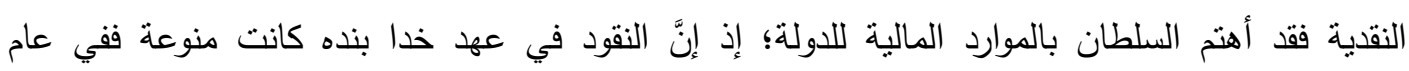

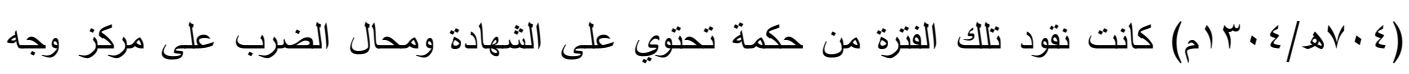

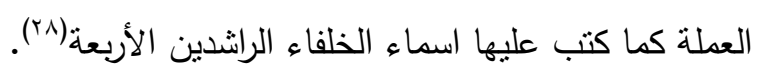

وشهر عهد السلطان خدا بنده متغيرات سياسية ودينية غطت بظلالها على علية سك العملة النقدية لاسيما أنَّ السلطان خدا بنده كان متأثراً برجال حانشيته فكان يغير ولاءه لمذهبه وفقاً لآراء رجالات البلاد

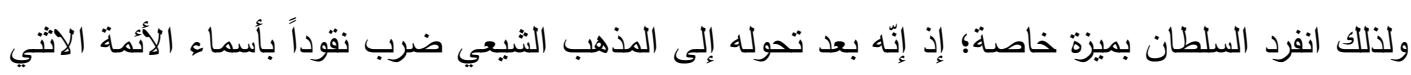

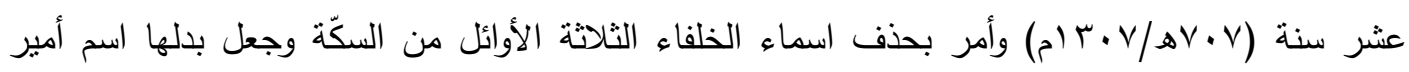
المؤمنين علي بن ابي طالب (ع) كما أمر برفع الإثارات التي تثير إلى القان الأعظم وأصبح النفس اسلامياً

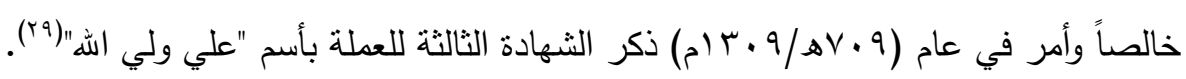

ومن ثم فِانَّ تحول السلطان خدا بنده إلى المذهب الثيعي جعله في محل مواجهة الكثير من المشاكل داخل بلاده الأم بلاد فارس مما دفع بعضهم في الخروج عن طاعته وتتفيذ أوامره لا سيما أنَّ أغلبية

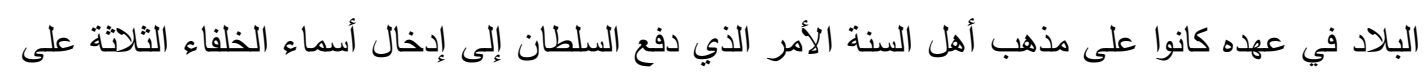
السكّة في محاولة من السلطان تخفيف حالات التمرد التي بدأت تظهر بسبب إجراءاته التي اتخذها حول سكّة التهاء

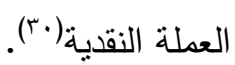

وفضلاً عن النقود الذهبية تعامل الحكام الإيلخانيين بالنقود الفضية وهذه النقود لم تكن إلا استمراراً

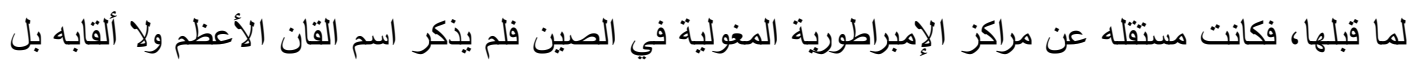

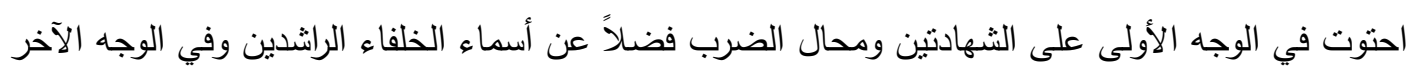

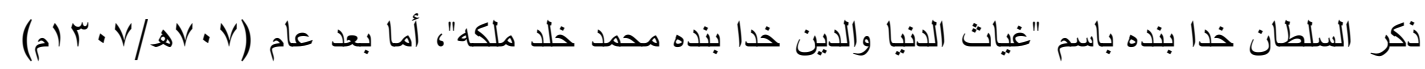

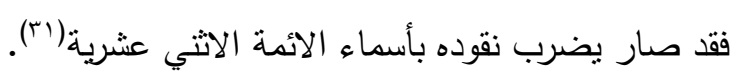


وعلى الرغم من التغيرات التي جدت على العملة المغولية إلا أنَّ العملة في البلاد الإسلامية حافظت على عباراتها المعروفة بنقوش عبارة "لا إله إلا الله محمد رسول الله" باسنثتاء نقود السلطان خدا بنده التي حوت على اسماء الأئُة الاثتي عشرية التي أُضِيْفَت إليها بعد ذلك اسماء الخلفاء الثناثةة(rr).

وإلى جوار النقود الذهبية والفضية كانت هنالك النقود النحاسية إلا أنَّ كثرة استخدام المغول للنقود الذهبية والفضية قلل من استخدامهم للنقود النحاسية ومع استقرار النقود الفضية ألغى المغول سكَ الدرهم النحاسي إلا أنَّ بعض المصادر أشنارت إلى أنَّ السلطان خدا بنده ضرب نقوداً نحاسية عام (• ( اهـ/ • ( ام) حملت لقب السلطان الأعظم، ومن ثم فُأنَّ تداول الدراهم الذهبية والفضية في الأسواق قلل من الاعتماد على النقود النحاسية التي باتت في تلك الفترة نادرة الوجود قياساً مع الدراهم الذهبية والفضية(r).

وفي ظلَ النفوذ المغولي للعراق منلت الضرائب رأس الهرم في النظام الإداري في حكمه للبلاد التي أخضعوها لنفوذهم فكانت الضرائب في العهد الإيلخاني استمراراً للضرائب التي كان يتبعها العباسبين في أواخر حكمهم فلم يختلف نظام الضرائب المعمول به من قبل الإيلخانيين عن ما كان موجود في البلاد أيام حكم العباسبين إلا أنَّه ما يؤخذ على ضرائب الحكم الإيلخاني أنَّه كان أكثر ثقلاً وخضوعاً لأهواء الحكام فكانت الضربية تزداد وفق لما براه الحكام ضرورياً له وما يوفر له الاموال اللزمة التي تهيأ له الطريق دون مواجهة مشاكل مالية تجعله يواجه المصاعب في إدارته لإقليمه الحاكم(عَ).

وذكرت المصادر التاريخية أنَّ الضرائب التي وردت اسماؤها إبان حكم المغول للعراق هي ضريبة الأرض والخراج(ro). وضريبة الرؤوس(rr). وضريبة البيوت وضرائب فرضت على الأسواق والمراعي وضرائب فرضت على الموظفين الذين ينت مصادرة أموالهم فضلاً عن ضرائب كانت تؤخذ من غش

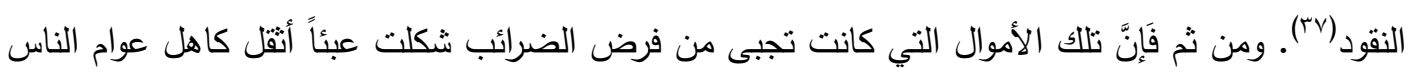
في العراق الذين وجدوا أنفسهم بعد دخول المغول اليهح أمام مصاعب سياسية القت بثقلها على معيشهم الاقتصادية فزادت من سوء أحوالهم الاجتماعية. 
واتسعت الأزمات المالية الإدارية في العراق مع توطيد النفوذ الإيلخاني في البلاد تمنلت تللك الازمات بتتوع الضرائب التي لم تقف عند حدود ضريبة الخراج أو الجزية فحسب بل شملت جوانب عديدة

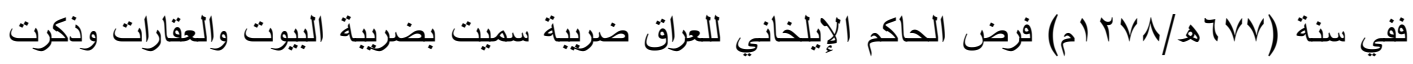

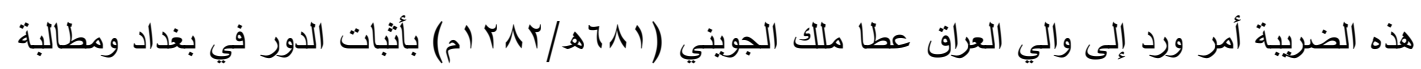

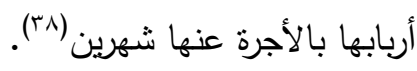

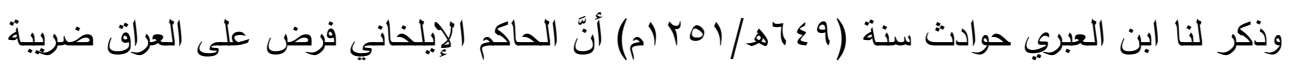
تُسَّمى ضريبة المراعي أو ما يسميها المغول "القيجور" وجاءت هذه الضريبة وجاءت هذه الضريبة بعد تعين

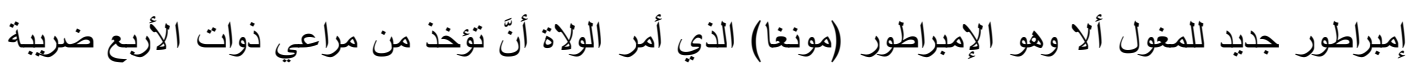

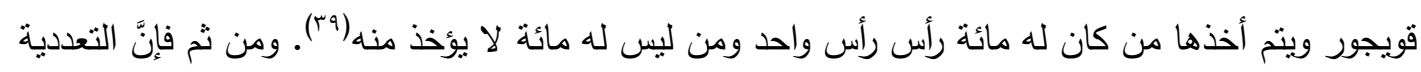
في أنواع الضرائب المفروضة على أهل العراق إبان الحكم الإيلخاني أدى إلى حدوث ازمات مالية متكررة

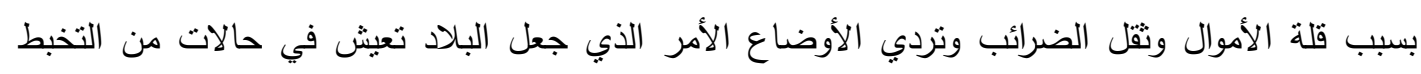

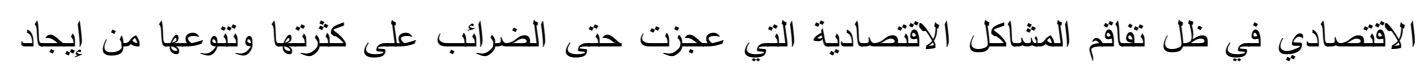
الحلول المناسبة لها.

وفي ظلّ حديثا عن الضرائب التي اعتمدها الحكام الإيلخانيين في العراق بّد من القول إنَّ نظام

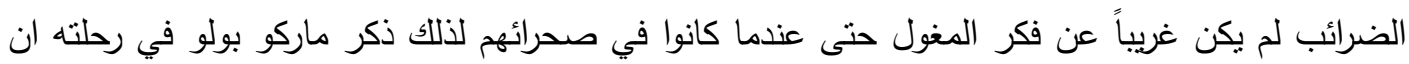
الدغول كانوا خاضعين في فترة من فترات حياتهم لملك يعرف باسم (اونك خانا) وكانوا يدفعون له الضريبة

$$
\text { ومقدارها عشر من كل شيء عندهم(·ـ). }
$$

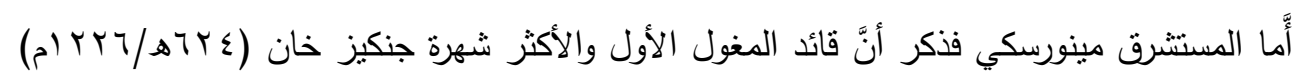
عرف هو واتباعه الضريبة التي فرضوها على الثعوب بعد أن اخضعوها لنفوذهم لا سيما تلك الضرائب فرضت على اعبان القوم الأكثر نفوذاً ومالاًا("). ومن خلال نتبعي للأحداث السياسية والعسكرية للمغول إبان ظهورهم على الساحة نبيّن بأنَّهم عرفوا نظام الضرائب منذ قت طوديل؛ إذ إنّهم اجبروا على دفع الضريبة 
لأباطرة الصين عندما كانوا يعيشون كقبائل ضعيفة تحتاج إلى مد يد العون والمساعدة التي كانت تقدم من

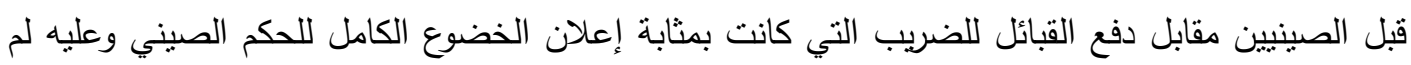
يكن فرضهم للضرائب بكل أثكالها بالثيء الجديد إنَّما نوع الحكام الإيلخانيين لطرق فرض وجبائ إعلية الضرائب

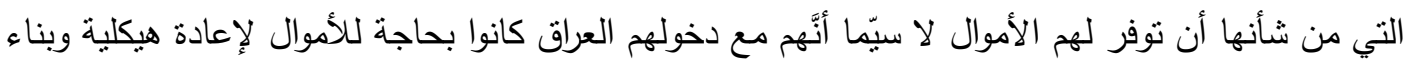
الدولة وفق الأطر التي حددها إيلخان المغول لحكام الولايات الخاضعة لهم.

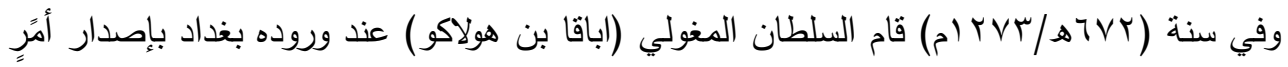
تم بموجبه بالإحسان إلى الرعية وتخفيف ضريبة التمغات(؟^). وحذف الاثقال عنهم لا سيّما أنَّ الضرائب كانت تزداد بسبب ظلم الضامنين لها؛ إذ إنهم عمدوا إلى زيادة الضرائب لتحقيق مكاسب خاصة لهم فظلاً عن جمع أكبر قدر ممكن من المال الذي تحتاجه البلاد لسدّ احتياجات الخاصة والعامة.

وعمل السلطان محمود غازان في حدود سنة (ع . هـ/ r.r ام) على إصدار نصّت ديباجة ذلك

القانون على ضرورة إصلاح نظام الضرائب ليس في الولايات التابعة للحكم الإيلخاني فحسب بل شمل الأمر

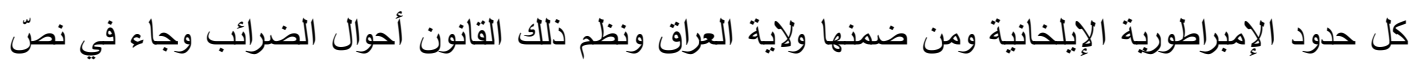
القانون بأنَّ الهدف من إصداره والتأكد من نطبيقه هو الرغبة في تقرير أموال الممالك وأحوالها ودفع الجور وأنواع الكلف الديوانية و إزالة الضرائب الزائدة التي كان يجمعها الجباه لأنفسهم وأنَّ موظفي الضرائب أرسلوا إلى جميع الممالك ليقوموا بتحديدها وتفصيلها في كل ولاية ومدينة لكي لا يظل هنالك مجال للجباة بأخذ مبلغ أكثر منها وأن ميعاد دفع الضرائب بموجب هذا القانون يحدد كمية الضرائب المفروضة (َّ). ويبدوا واضحاً أنَّ السلطان غازان من خلال إصداره لذلك القانون حاول إصلاح نظام الضرائب وتخفيفه من كاهل الناس في عموم البلاد الخاضعة لنفوذ إمبراطوريةٍ لأمرين الأول لإظهار حكمه بصورة التي تجعله محبباً في قلوب

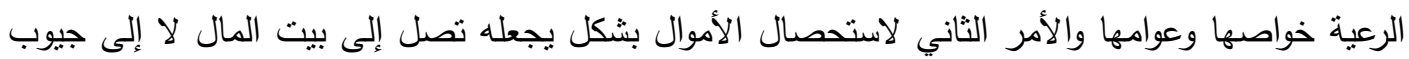
الجباة الذين تمادوا في جمعهم 
سعى الحاكم الإداري في العراق وبأمر من الحكام الإيلخانيين إلى أجراء الاصلاحات الإدارية التي من شأنها تحسين أوضاع البلاد اقتصادياً ومن ثم جمع أكبر قدر ممكن من المال مع وجود الاصلاحات التي من شأنها معالجات المشاكل الاقتصادية التي أثزت كما كان يراها الحكام الإيلخانيين سلباً وأصبحت عائقاً في جمع أموال الولايات الخاضعة لنفوذ ادارتهم سياسياً واقتصادياً(ء).

حاول الحاكم الإداري للعراق إبان النفوذ المغولي القيام بجملة من الاصلاحات المالية لا سيما ان حاكم العراق آنذاك تمثل بشخصية تأريخية شهيرة إلا وهو خصية عطا ملك الجوبني الذي تولى إدارة العراق

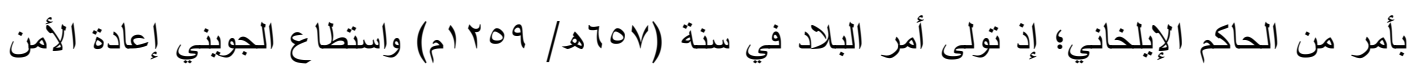
والاستقرار بداية تولية شؤون العراق فتوفرت خيراته وزاد رخاؤه حتى قيل إنَّ بغداد في عهده أصبحت اجود مما كانت عليه في ايام الخلافة(0؛). ويبدوا أنَّ رخاء بغداد في ظل حكم الجويني جاء للإجراءات التي اتخذها هذا الحاكم الإداري التي تمثلت أولاً بإعادة الأمن والاستقرار إلى البلاد بعد دخول المغول إليه ولا سيّما حالت الفوضى التي عمت البلاد في ظل النفوذ المغولي ولذلك عدت المصادر أنَّ عودت الامن والاستقرار إلى بغداد أحد اهم الاعمال الإدارية التي اثتتت تكاملية الأعمال الإدارية التي باشر بها بعد ذلك الجويني.

وفي الحديث عن إجراءات الجويني الاصلاحية في مواجهة الازمات الاقتصادية لابدّ من الحديث أولاً عن تثبيت دعائم الأمن والاستقرار الداخلي الذي هيأ له فرصة تحسين الأوضاع الداخلية ومن ثم القيام بما من شأنه إصلاح المشاكل التي عصفت بالبلاد ومن الناحية الاقتصادية ولأننا نعرف أنَّه من غير الممكن لأي حاكم وفي أي زمان ومكان القيام بمعالجة مشاكل بلاده اقتصادياً دون أن يوفر أرضاً أمينة ومستقرة كخطوه أولى لأي عملاً اصلاحي يسعى إليه ليس الجويني فحسب بل كل حاكم ينولّى الثؤون الإدارية يبدأ أولاً من الأمن والاستقرار ثم يسعى بعد ذلك لمعالجات اقتصادية وهكذا بدأ الجويني طريقة الإصلاحي من قاعدة توفير الأمن والاستقرار للبلاد التي تولى إدارتها سياسياً وعسكرياً واقتصادياً. 
أصبح الجويني هو الحاكم الحقيقي للعراق وجعله حاكماً للبلاد جاء بسبب ما تمتع به من حسن

\section{مجلـــة كليـــة التربيـــة}

التصرف والثخصية القوية التي عرف بها لا سيما أنَّ الجويني كان قد تولى منصب الوزارة في بلاط الخان

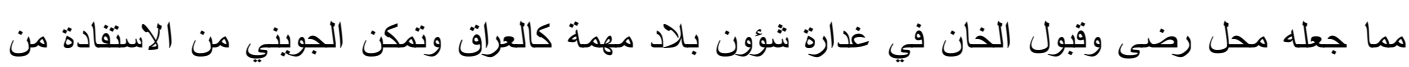

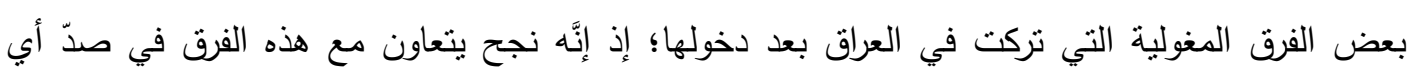
هجمات ممكن ان تتعرض لها البلاد التي كانت مفتوحة آنذاك على الكثير من الأعداء بالنسبة للمغول

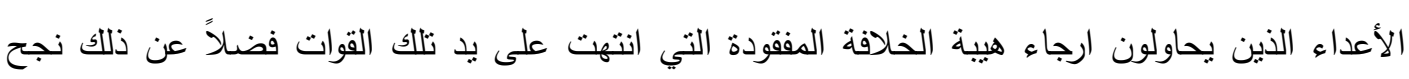
الجويني وبتتسيق مع صاحب الثرطة الذي كان من ابناء البلاد في حفظ الأمن في أطراف بغداد من لهن لهن اللصوص وإيقاف السرقات وملاحقة المجرمين والقتلة ومعاقبتهم وسجنهم (1؟).

وفي سبيل معالجة المشاكل الاقتصادية التي المت بالبلاد سعى الجويني لجملة من الاجراءات

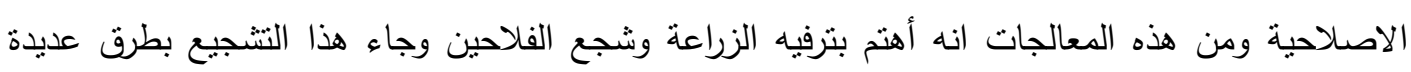

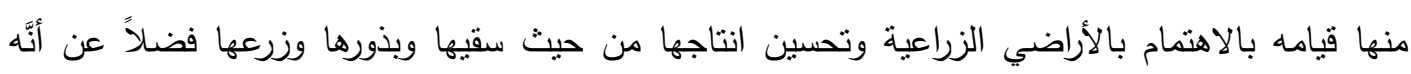
أسقط عن الفلاحين بعض من الضرائب التي انقلت كاهلهم واعجزتهم وألغى عنهم مطاليب الديون الني بالئي جعلت الفلاحين يتتفسون الصعداء بعد أن خفف من ديونهم التي شجعتهم لمزاولة العمل الزراعي وتحسين

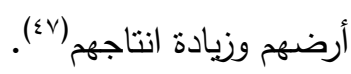

ولم يقف الجويني في معالجته الاقتصادية عند حد الأرض بل عمل على فتح قناة من الفرات في أعلى الانبار لسحب المياه حتى الكوفة والنجف أنفق عليه أكثر من مائة ألف دينار وانثأ على جانبيه أكثر من مائة وخمسين مزية وعليه استطاع الجويني في ظلّ هذه الاجراء من إحياء أراضي شاسعة وأوجد موارد للخزينة (§)

واصل صاحب الديوان والحاكم الإداري للعراق الجويني اصلاحاته لتنّمل إعمار بغداد واصلاح ما تهلم من مدارسها ومساجدها وعمل على بناء عدد من القصور والبساتين كما عمل على إعادة بناء منارة

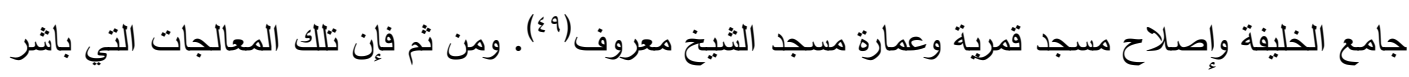


بها الجويني جعلت بغداد تعيش شيئًا من الاستقرار الاقتصادي إنْ صحٌ التعبير إلى جانب الاستقرار الأمني الداخلي الذي نجح الجويني في تحقيقه في عموم البلاد.

وفي ظلّ نلك المعالجات التي قام بها الجويني في الجانب الاقتصادي عمل على تتظيم ايصال المياه إلى بركة المستصرية بإنثاء دولاب تحت مصفاتها لرفع الماء إليها من دجلة وقد أصدر الجويني أمراً بإعادة بناء وعمارة المدرسة النظامية التي أصابها الحرق بعد أن تعرض السوق المجاور لها للحرق وتأكلته النيران فأمر ليس بعمارة الددرسة النظامية فحسب بل بإعادة إعمار السوق الذي تضرر جراء ذلك الحريق ولكي يتفادى الجويني وقوع مثل تلك الحوادث أو على أقل تقدير التقليل من الخسائر التي بمكن ان بتعرض لها الناس جراء ذلك أمر ببناء حياض للماء في دروب بغداد لكي تحقق الفائدة منها في إطفاء الحرائق فيما إذ حدثت في تلك الأماكن (0.).

كما وسعى الجويني في باب اصلاحاته الاقتصادية إلى توسيع مدينة بغداد؛ إذ أمر ببناء بعض

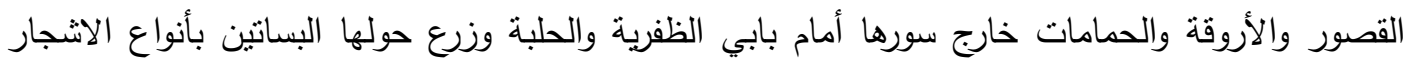
المثرة حتى أصبحت مثتزهاً لسكانها (0).

إنَّ معالجات الجويني الاقتصادية لم تقف عند حدود بغداد بل شملت انحاء من العراق؛ إذ إنَّه أظهر اهتمامه بعمارة موضع في نهر جعف من إعمال واسط سماه المأمن وبنى فيه ديواناً وجامعاً وخاناً وحماماً وسوقاً فسكنه وانتفع به الناس والتجار الذين كانوا يترحلون في تجارتهم واسفارهم ما بين البصرة وواسط مما هيّأ لهم طريقاً آناً حفظ لهم اموالهم من السرقة والضياع(هr).

وجها صاحب الديوان في اصلاحاته الإدارية؛ إذ انه قام ببناء رباط في مشهد الإمام علي (عليه السلام) ليسكنه المقيمون والمجاورون ومن أعماله في هذا المجال أمر ببناء جسر تم حمله إلى تستر

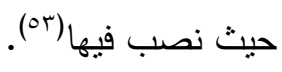


ولجئ الجويني في ظلّ اصلاحاته الاقتصادية إلى معالجة هرم الرأس الاقتصادي إلا وهي الضرائب

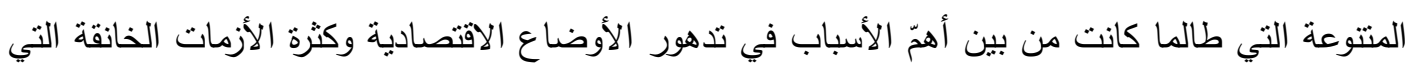

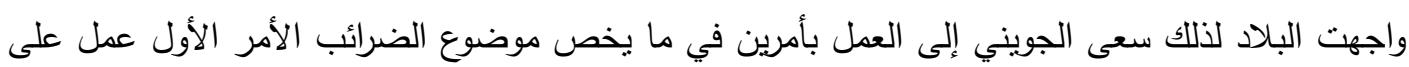

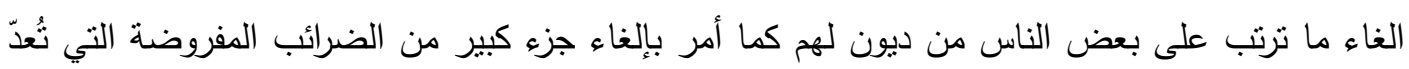

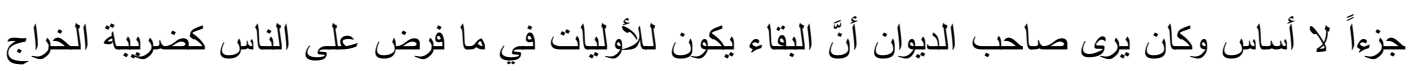

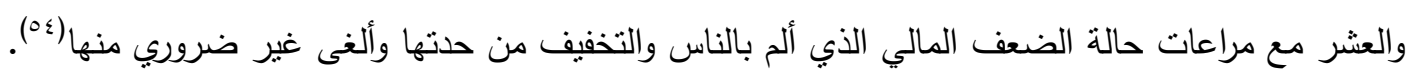

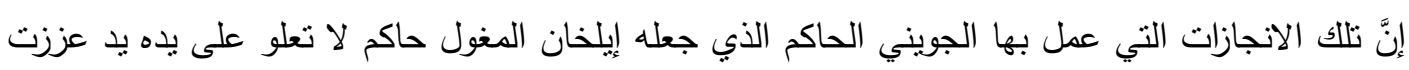

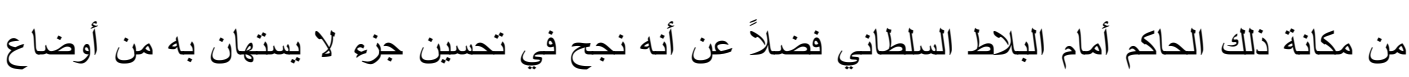

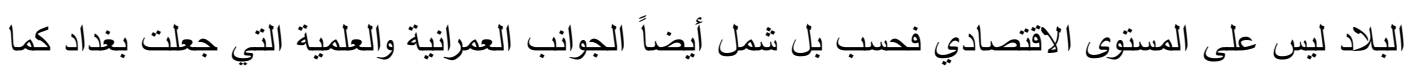
قال عنها بعض المؤرخين إنَّها عاشت إبان عهر الجويني أزهى ما كانت عليه أيام الخلافة.

ولم تقف جهود الجويني عند حذّ الاصلاحات الإدارية لأمر الضرائب فحسب بل شملت اصلاحاته الجانب الصناعي لا سيما أنَّ الحياة الصناعية في العراق تدهورت بشكل كبير نتيجة الاجنباح المغولي للبلاد

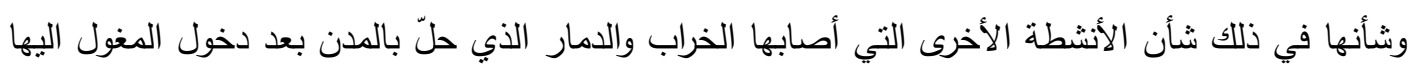

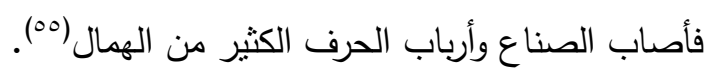

وسعى الدغول إلى محاولة إصلاح الجانب الصناعي في ظلّ الإدارة الجديدة للبلاد فعملوا على المحافظة على أرواح الصناع للاستفادة منهم وأظهروا اهتمام بالصناعة والفنون وفي هذا المجال شجع

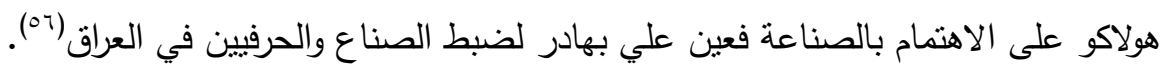

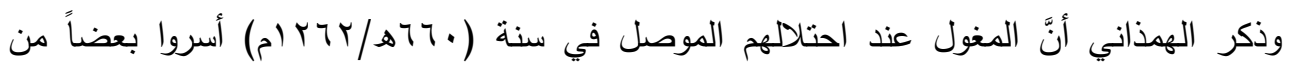
ارباب الحرف والصناعات ولابدّ من القول إنَّ المغول اعتادوا منذ أيام مؤسس دولتهم جنكيز خان أن لا يقتلوا كل من كان صاحب مهنة أو من التجار وجعل جنكيز خان أمر اسرهم ونقلهم إلى عاصمنهم الأم قرقورم

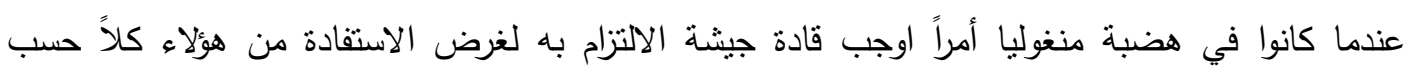




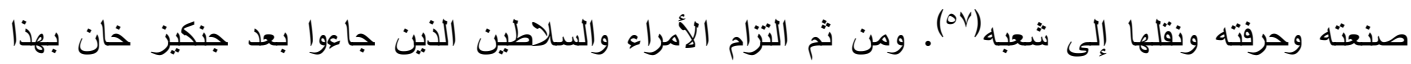
الأمر لذلك نرى أنَّ هولاكو يتبع نفس السياسة في ما يخص أصحاب الصنعة وحنه وارباب الحرف سواء في أسرهم أو إظهار مدى الاهتمام بالجانب الصناعي عند دخولهم بغداد.

ولقد تمكنت بغداد ومناطق العراق الأخرى من استعادة شيء من نثاطها نتيجة لجهود التي بذلها الجويني في إعمار ما خرب وإعادة الأسواق وتتجيع أصحاب الحرف والصناعات وأظهر الجويني اهتماماً

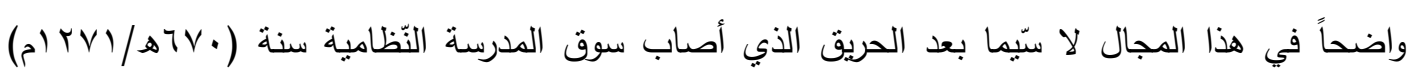

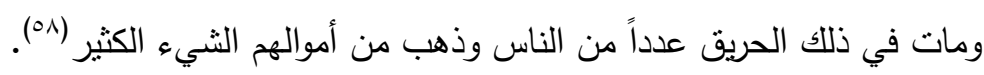

وبعد وقوع ذلك الحريق عمل الجويني على الاهتمام بإعادة إعمار من حاصل وقف المدرسة

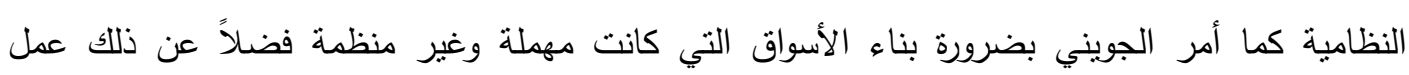
الجويني على توفير رؤوس الأموال لأصحاب الصناعة والحرفيين الذي لم تكن لديهم الأموال الكافية لممارسة الدهاء

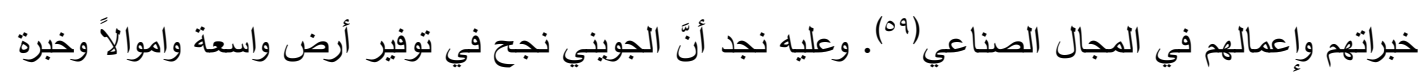
لغرض انعاش الحياة الصناعية الني بدأت تستعيد مكانها بين المجالات الاقتصادية الأخرى

ومع تعرض الحياة الصناعية في بغداد إلى الخسارة في بداية الاجنياح المغولي لها إلا أنَّ بعض المدن العراقية الأخرى حافظت على مكانتها الصناعية ولم تخسر الكثير من الايدي الصناعية كالبصرة والكوفة والحلة لعدم تعرضها لتدمير أو دخول الدغول اليها نتيجة عدم مقاومة الجيش المغولي أثناء اجتياحهم

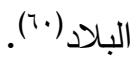

ومع وجود كلٍّ من البصرة والكوفة والحلة استعادت بغداد بفضل الجهود التي بذلها الجويني مكانتها

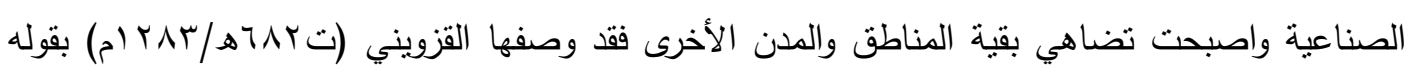
"والآن هي مدينة عظيمة إذ ما من مناع ثمين ولا غرض نفيس الا ويحمل اليها فهي مجمع لطيبات الدنيا ومحاسنها ومعدن لأرباب الغايات واحاد الدهر في كل علم وصنعة"(1). 
ولم تقف اصلاحات المغول عند حدّ الباب الصناعي فحسب بل اظهروا اهتمامهم بالنشاط التجاري؛

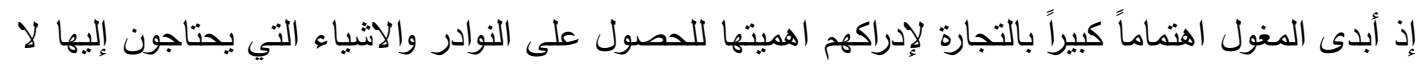

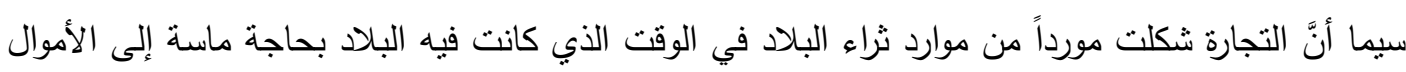

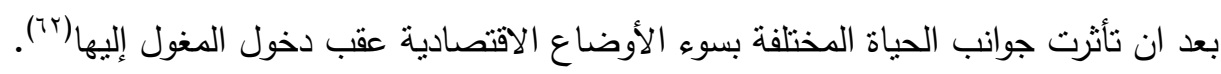

جهد الحكام المغول بعد دخولهم بغداد واستقروا فيها إلى محاولة منهم اصلاح الأوضاع الاقتصادية ومنها التجارة والعمل على إعادة نشاطها من جديد فعملوا حكامها على تقديم التسهيلات التجارية لكّل التجار والتجارة الداخل للبلاد وأصبحوا يتمتعون بمنزلة عالية من الاحترام والتقدير من قبل الناس والحكام معاً بما يهل عمهم التجاري سواء في تجارتهم الداخلية أو الخارجية فضلاً عن تقليل ما عليهم من ضرائب ورسوم على البضائع الداخلة للبلاد والخارج منها ممّا عزّز وسهل من عمل التجار في بغداد والمدن الأخرى بشكل جعل البلاد محطة لتنداول السلع والبضائع بيسر وسهوله ولقد تركز النشاط التجاري في المدن التي شكلت

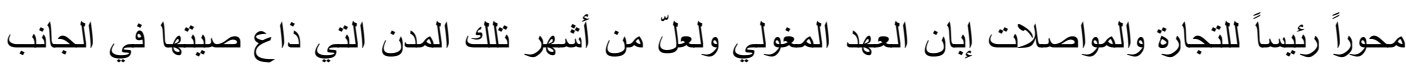
التجاري خلال تلك الفترة هي كلاً من بغداد والبصرة والكوفة وواسط ومدن وطرق خراسان أما بغداد فكانت هي محور ومركز النشاط التجاري فضلاً عن ذلك كانت الحركة التجارية واسعة في مدينتي نكريت والموصل(Tr(7) ومن ثم نجح الحكام المغول في تتشيط الحياة التجارية والمحافظة على طرقها من السلب

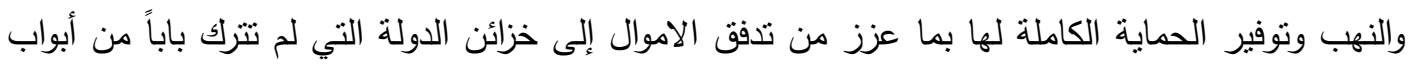
الحياة الاقتصادية إلا وكان لها فيها اصلاحات من شأنها إنَّ تعالج الازمات المختلفة التي مرت بها إبان دخولها العراق وعليه لا بد من القول ان المغول نجحوا في حلتت ومواجهة الكثير من الأزمات الاقتصادية التي عانت منها البلاد في فترات حكمه بالاعتماد تارة على بعض الثخصيات القيادة ممن نولى حكم العراق

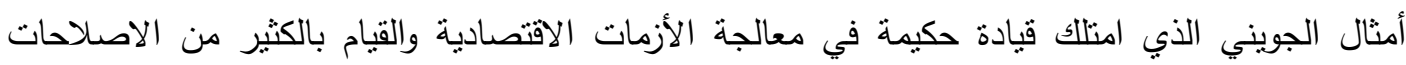

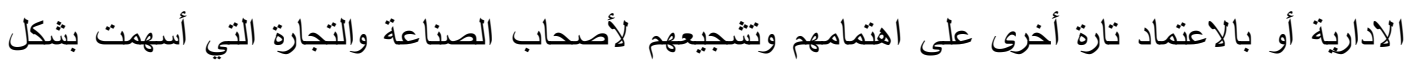
واضح في معالجة المشاكل الاقتصادية وايجاد الحلول المناسبة لها بما وفرت لهم من اموالٍ واستثمارات داخل البلاد التي فرضوا نفوذهم عليها. 


\section{"الفاتمة"}

مجلـــة كليــــة التربيـــة

في ختام بحثنا الموسوم (الأزمات الاقتصادية في العراق أثناء حكم المغول وسبل معالجتها) لا بد من تسجيل أهم النتائج التي توصلنا اليها وهي:-

ا- ارتبطت الأوضاع الاقتصادية لكلّ بلاد في البلدان وفي كل عصر من العصور بالاستقرار السياسي

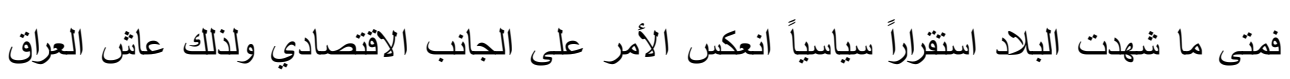

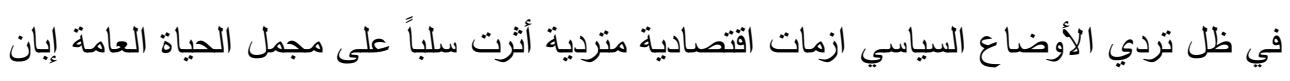
العصر الإيلخاني واجتياح المغول للبلاد.

r- حاولت السلطة الإيلخانية عقب استقرارها في العراق القيام باصلاحات إدارية في محاولة لتحسين وانعاش الوضع الاقتصادي السيء الذي عصف بالبلاد بعد اسقاطهم الخلافة العباسية وتحويل

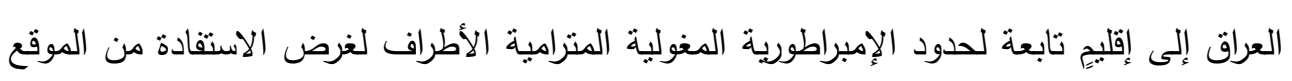

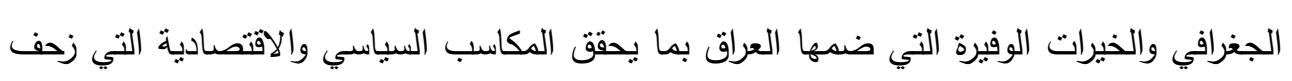

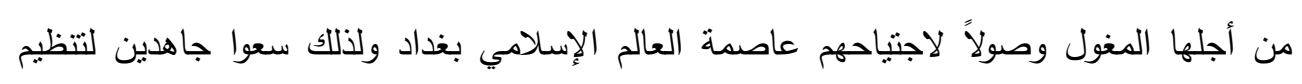
البلاد إدارياً واقتصادياً بما يضمن لهم الحصول على تلك المكاسب الاقتصادية. لهادئ.

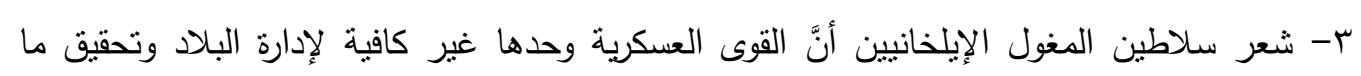

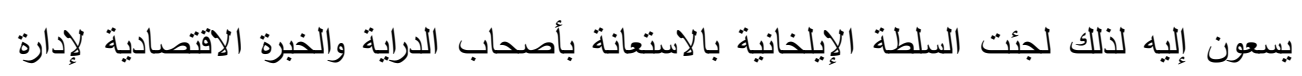

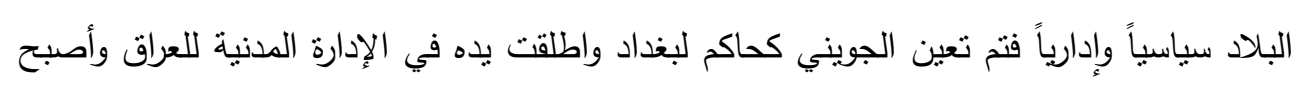

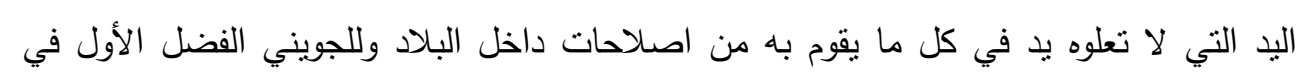

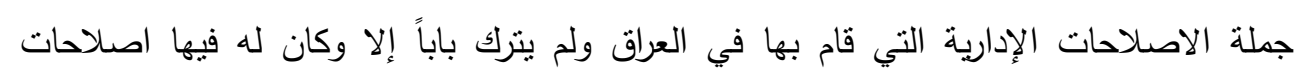

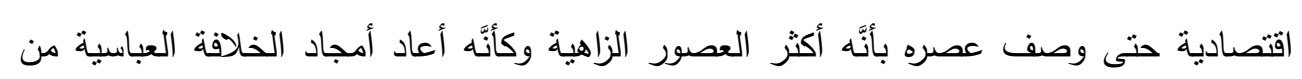


ع- أظهر الحكام الإيلخانييون اهنماماً واضحاً في الحياة الاقتصادية لمعالجة مشاكلها لذلك وفي محاولة

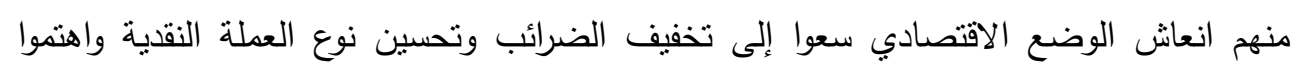

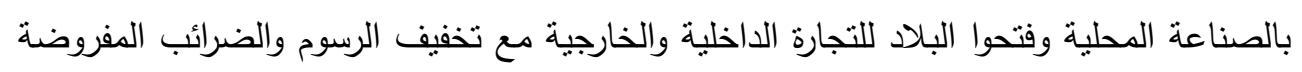

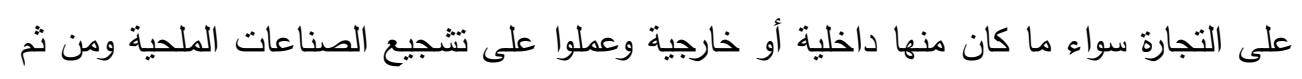
نجح المغول في ما قام به من إجراءات من نتئيت موطن استقرار نفوذهم فضلاً عن امتصاص

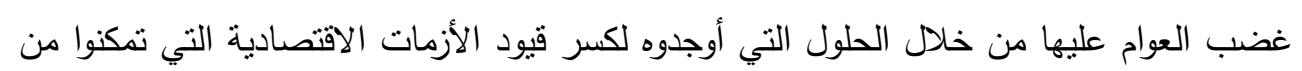
خلال إجراءاتهم تللك من معالجتها. 


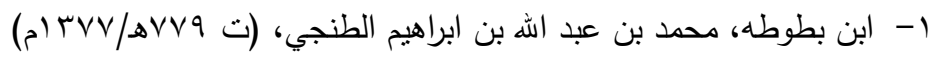

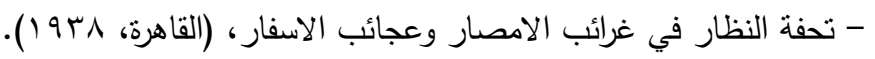

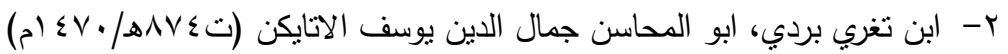

- - النجوم الزاهرة في ملوك مصر القاهرة، المؤسسة المصرية للتأليف والترجمة والطباعة والنشر، القاهرة،

$(1974$

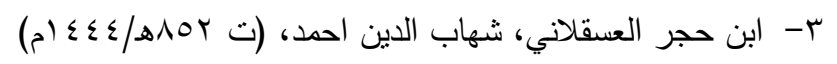

- - الدرر الكامنة في اعيان المائة الثامنة تحقيق سيد جار الحق، دار الكتب الحيثة.

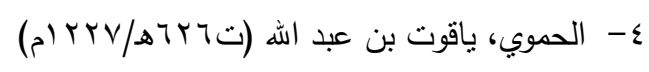

- معجم البلدان، دار احياء التزاث العبي (بيروت، بلا،تات)

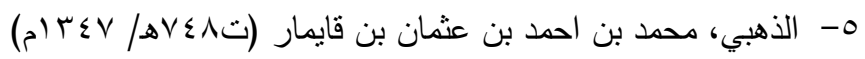

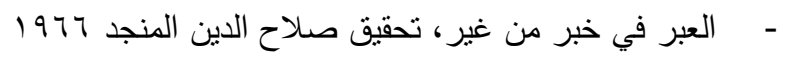

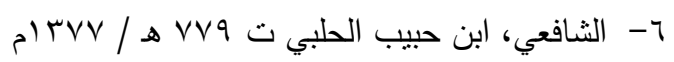

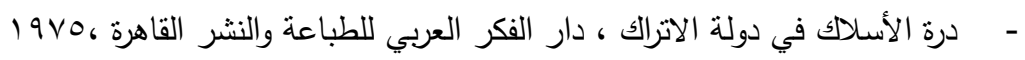

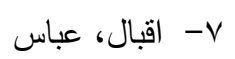

- - تاريخ المغول منذ حملة جنكيزخان حتى قيام الدولة التيمورية، ترجمة عبد الوهاب علوي، الهمع

$$
\begin{aligned}
& \text { الثقافي، (ابو ظبي، .... (†) } \\
& \text { 1- انور، عطا محمد }
\end{aligned}
$$

- احوال العراق الاقتصادية في ظل الاحتلال المغولي، دار العلم للطباعة والنشر ، (بيروت، ه . ب)

$$
\text { 9- بارنولد، ثيولر }
$$

- - تاريخ الحضارات الاسلامية، ترجمة حمزة طاهر، دار المعارف، (القاهرة، د-ت)

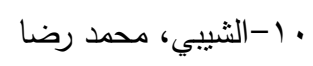


- اصول اللفاظ اللهجة العراقية، مطبعة المجمع العلمي، (بغداد، 1907)

$$
\text { 11- النبراوي، رأفت محمد محمد - }
$$

- النقود الاسلامية منذ القرن السادس وحتى نهاية القرن الثاسع الهجري، مكتبة زهراء الثرق، القاهرة ،د-

$$
\text { r ا-بتيس، مايكل وروبرت دارلي }
$$

- كنوز الفن الاسلامي، نرجمة حصه صباح السالم ونهادة صبحاوي قدومي، متحف راث، (جنيف،

$$
\begin{aligned}
& \text { (1910 } \\
& \text { rا-البكري، مهاب درويش } \\
& \text { - الالقاب على المسكوكات الايلخانية، مجلة سومر العدد( (r))، (بغداد، 1990) ) } \\
& \text { ؟ ا-القزاز ، محمد صالح }
\end{aligned}
$$

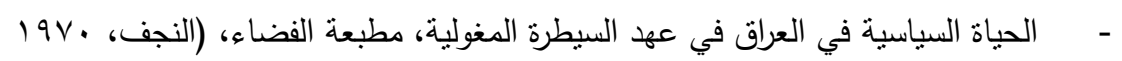

10-القيسي، ناهض عبد الرزاق

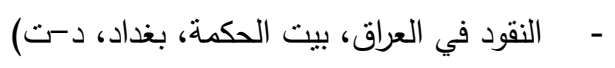

$$
\begin{aligned}
& 17
\end{aligned}
$$

- بلدان الخلافة الثرقية، ترجمة بشير فرنسيس وكوركيس عواد، مطبعة الرابطة، (بغداد، ؟90 (1) )

$$
\text { lv }
$$

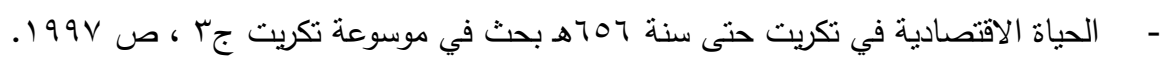

$$
\text { 11-الناصري، محمد عبد الجواد }
$$

- بغداد في ظل الاحتلال المغولي، دار التراث العربي للطباعة والنشر ، (بيروت، 990 (19 )

$$
\text { 19 ا-يوسف، احمد مهنا }
$$

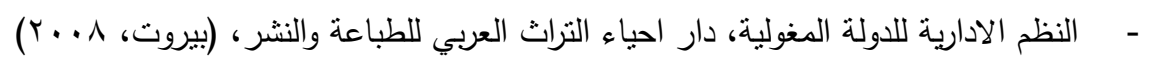

r-الربيعي، سهى خزعل نجيب.

- - العراق في عهز علاء الدين الجويني، اطروحة دكتوراه مقدمة إلى مجلس كلية التربية الجامعة

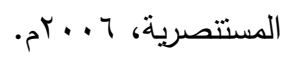




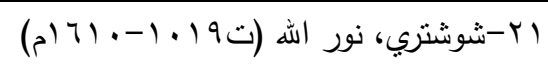

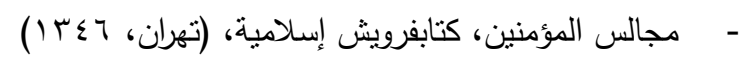
r r-طعمة، اسراء شهيد

- العراق في عهد السلطان خدا بندا، رسالة ماجستير ، كلية التربية جامعة بابل، ؛ ( بام

$$
\text { r r-عبد العزيز، ماجد }
$$

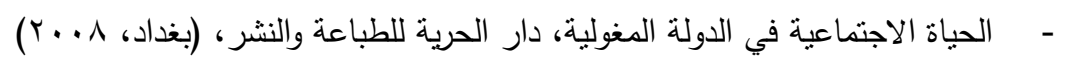

$$
\text { گ گ-العزاوي، عباس }
$$

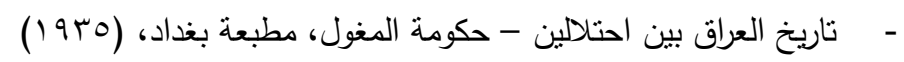

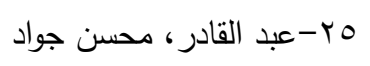

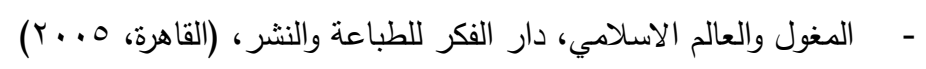

$$
\text { بr-الفيل، محمد رشيد }
$$

- - الحالة الاقتصادية لمدينة بغداد اثثاء الحكم الايلخاني، مجلة كلية الآداب، مطبعة العاني، (بغداد،

$$
\text { (197r }
$$

$$
\text { ب باولو، ماركو }
$$

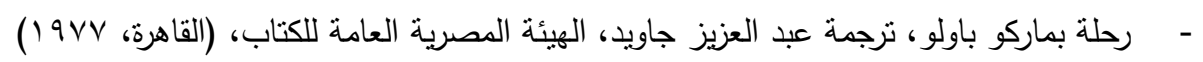

$$
\text { ^ץ- جواد، عبد الحسن }
$$

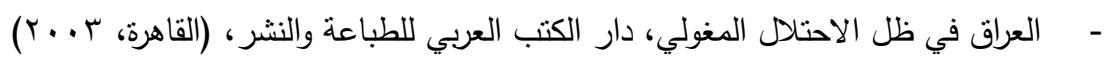

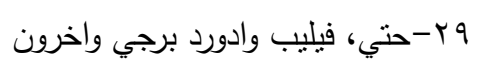

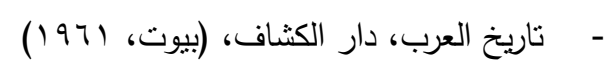

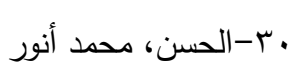

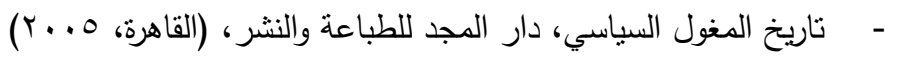

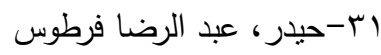

- العراق في عهد السلطان محمود غازان، رسالة ماجستير، (كلية الآداب، جامعة بغداد، 1991 (1) )

$$
\text { r ب الحسو، احمد عبد الله }
$$


- الصناعات في العراق منذ القرن الاول الهجري حتى القرن السابع الهجري، بحث في كتاب العراق في

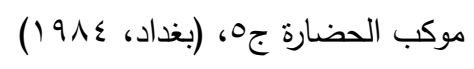

זr-خصباك، جعفر

- - العراق في عهد المغول الايلخانيين، مطبعة العاني، (بغداد، 971 (1) )

؟ ؟-رمضان، عاطف منصور محمد

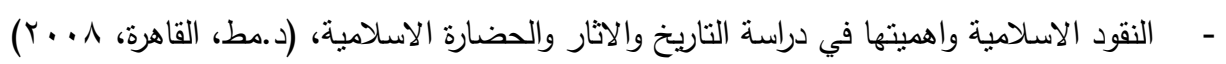

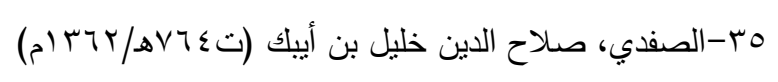

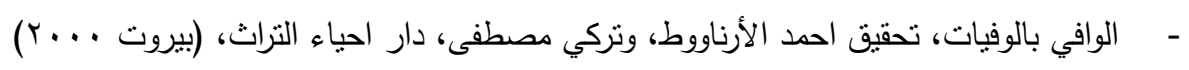

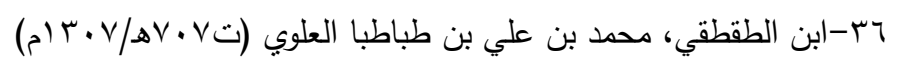

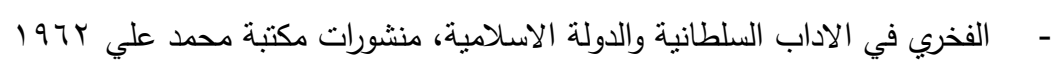

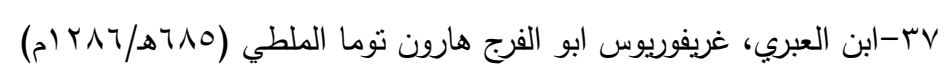

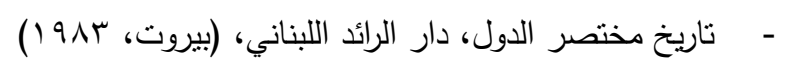

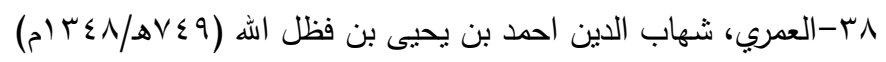

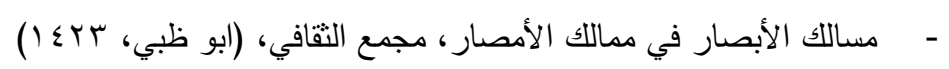

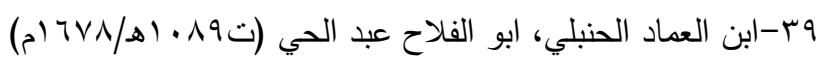

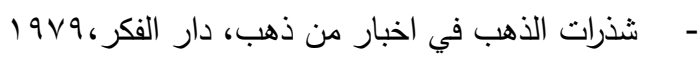

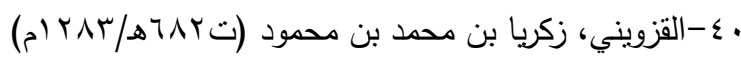

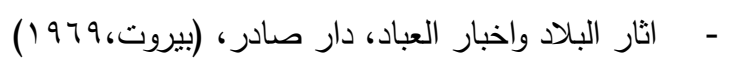

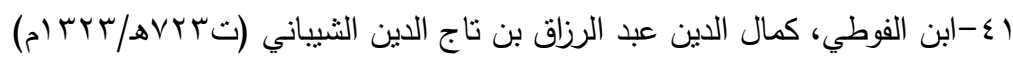

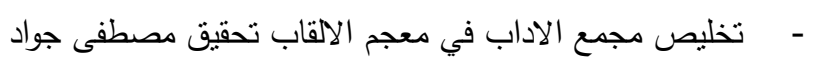

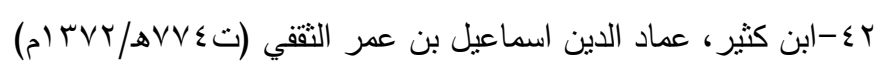

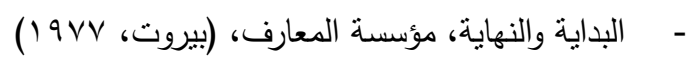




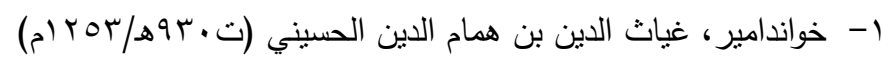

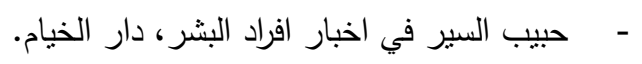

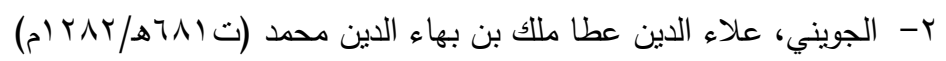

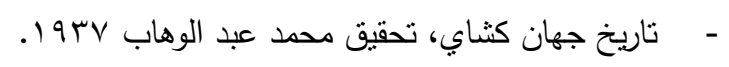

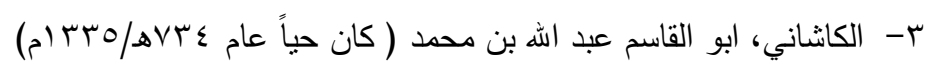

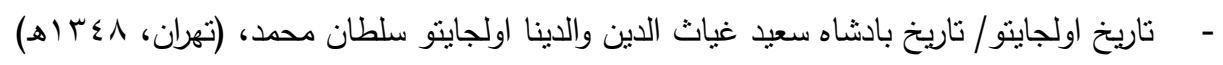

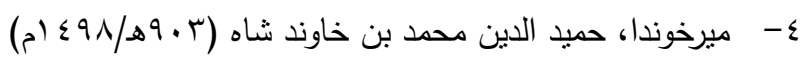

$$
\begin{aligned}
& \text { - روضة الصفا، جاب بميي باب أهـ }
\end{aligned}
$$

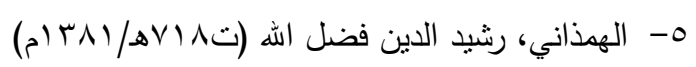

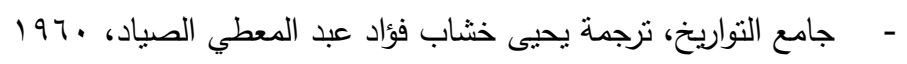

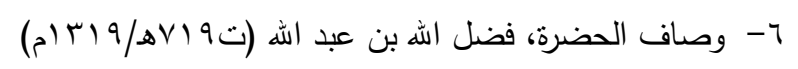

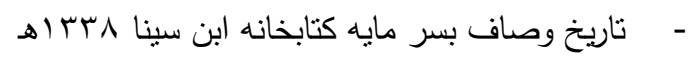

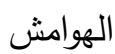

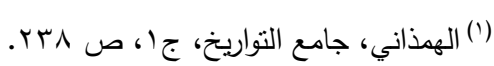

$$
\begin{aligned}
& \text { (") القزاز ، الحياة السياسبة في العراق، ص بr 1. }
\end{aligned}
$$

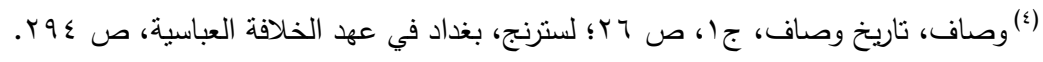

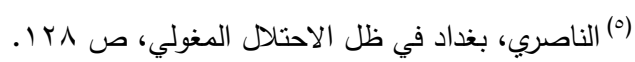

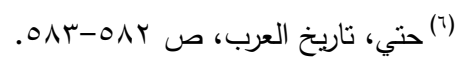

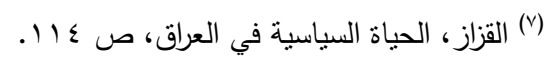

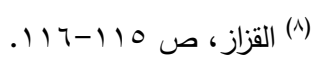

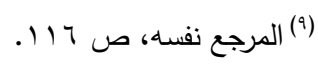


(*) البطائح هي أرض واسعة بين واسط والبصرة وقد سميت بطائح لأن المباه تسطحت إلى إن سالت واتسعت في الأرض. الحموي،

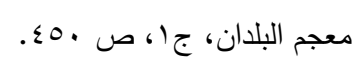

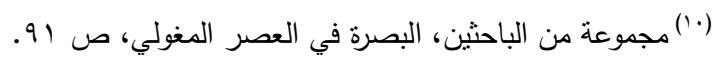

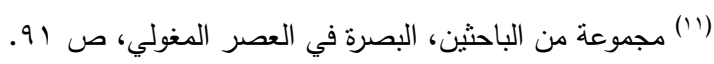

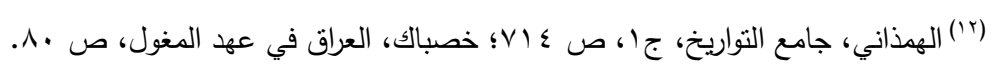

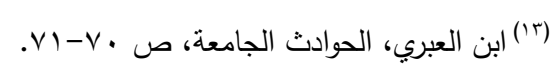

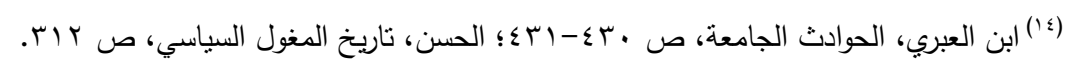

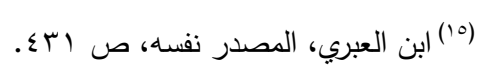

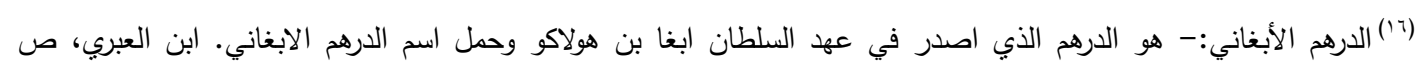

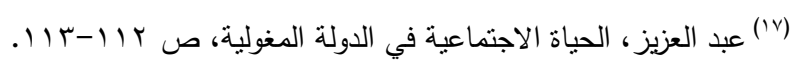

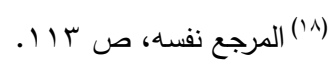

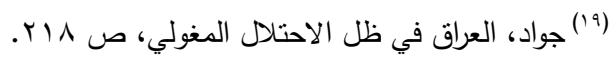
(·r) العوال:- هو عملة نقدية بقيمة أثثى عشر درهم كل درهم قيراطان وكل قيراط ثلاث حبات وكل حبه اربعة فلوس. ابن العبري،

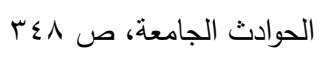

(rآ) المرسل:- هو دينار اصدره المغول وكان يساوي عشر دراهم وكانت به اكثر معاملات أهل بغداد وتجارها. ابن فضل اله

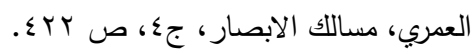

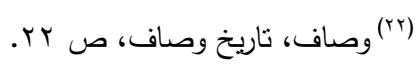

$$
\begin{aligned}
& \text { (r) }
\end{aligned}
$$

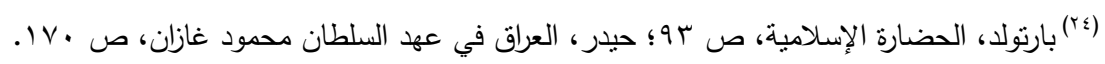

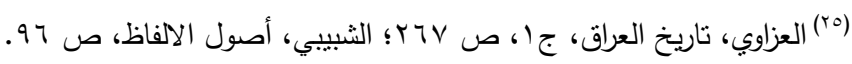

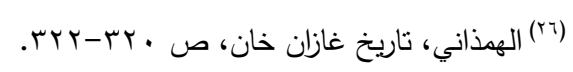

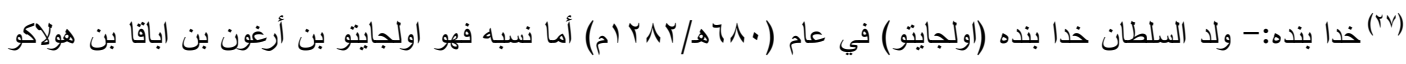
بن تولوي بن جنكيزخان واختلفت الآراء في أصل معنى الاسم باختلاف معتقده بعض الكتب فسر على ان معنى (خدبنده) انه عبد

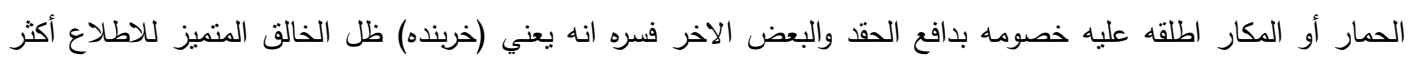

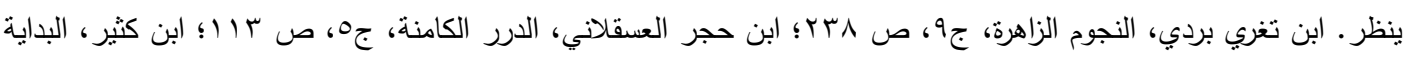




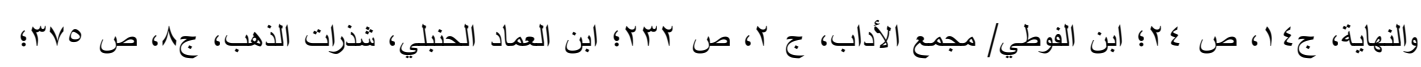

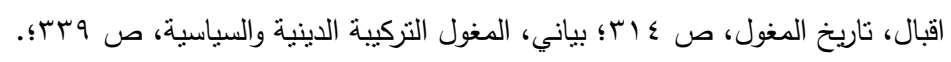

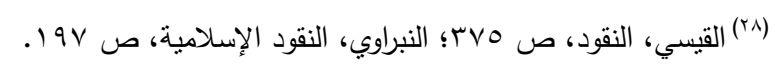

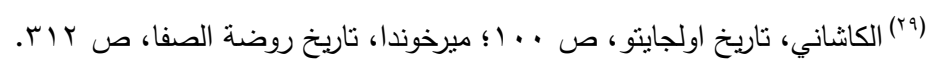

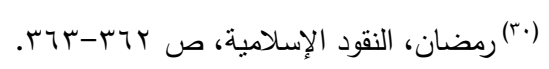

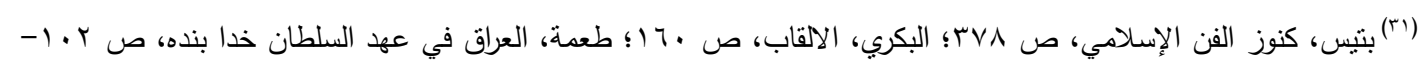

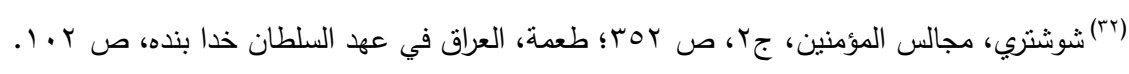

$$
\text { (rr) }
$$

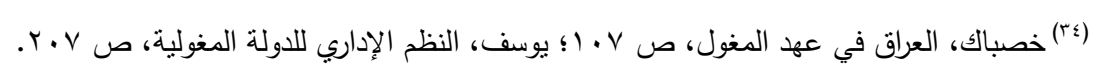

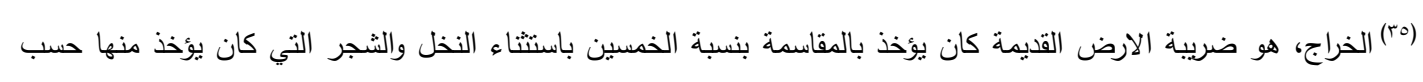

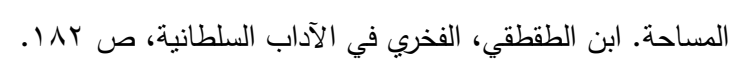

(َّ(ضريبة الرؤوس:- وهي الجزية التي كانت تفرض على أهل الذمة فقط ايام العباسيين فأنها أصبحت تشمل الجميع دون تميز

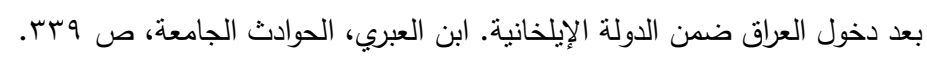

$$
\begin{aligned}
& \text { (بr) }
\end{aligned}
$$

(r^)

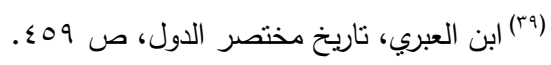

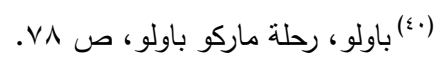

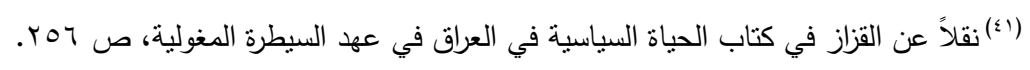

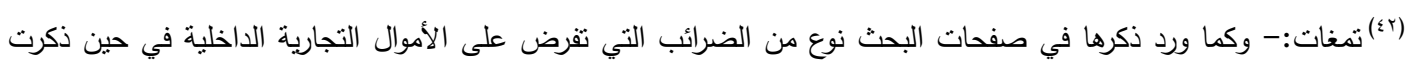

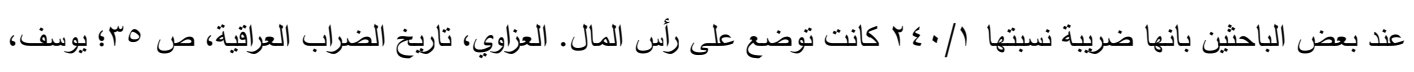

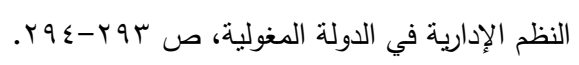

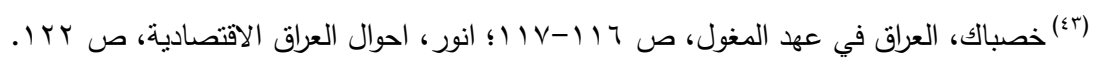

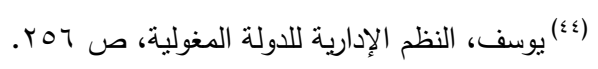

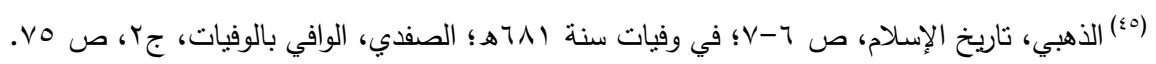

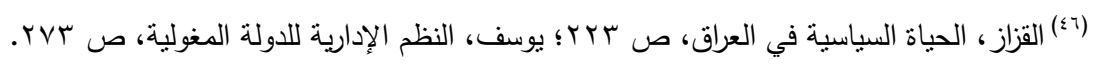




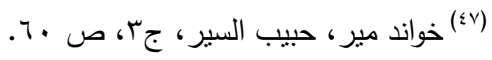

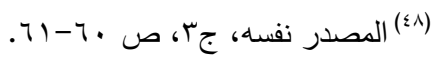

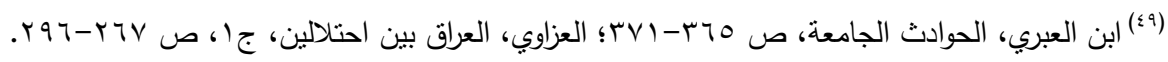

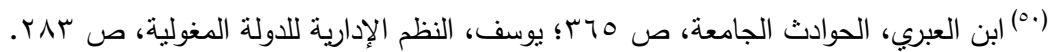

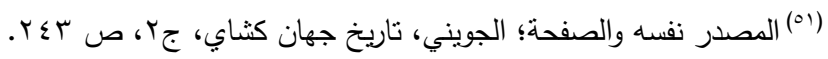

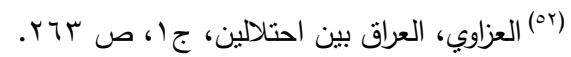

$$
\begin{aligned}
& \text { (or) }
\end{aligned}
$$

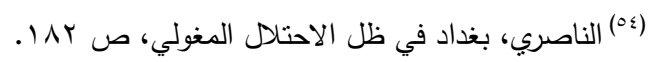

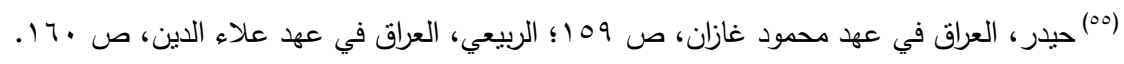

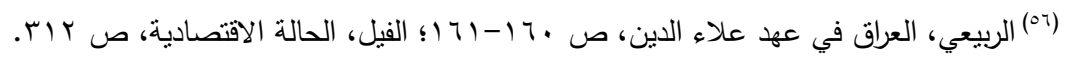

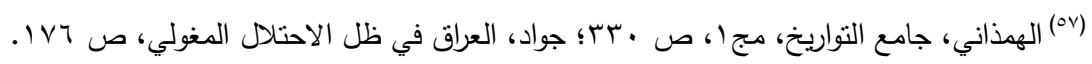

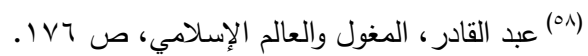

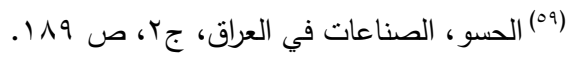

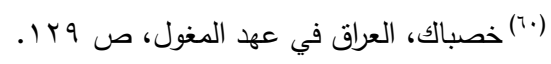

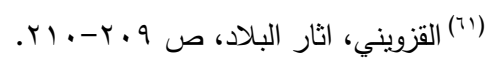

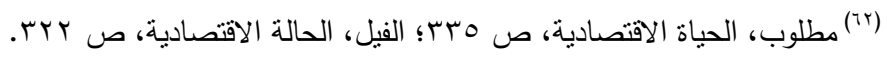

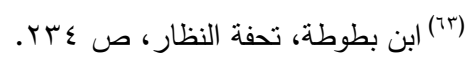

